\title{
Assessment of low-cost cartridge filters for implementation in household drinking water treatment systems
}

Afkhami, A., Marotta, M., Dixon, D., Ternan, N. G., Montoya-Jaramillo, L. J., Hincapie, M., Galeano, L., Fernandez-lbanez, P., \& Dunlop, P. S. M. (2021). Assessment of low-cost cartridge filters for implementation in household drinking water treatment systems. Journal of Water Process Engineering, 39, [101710]. https://doi.org/10.1016/j.jwpe.2020.101710

Link to publication record in Ulster University Research Portal

Published in:

Journal of Water Process Engineering

Publication Status:

Published (in print/issue): 28/02/2021

DOI:

10.1016/j.jwpe.2020.101710

\section{Document Version}

Author Accepted version

\section{General rights}

Copyright for the publications made accessible via Ulster University's Research Portal is retained by the author(s) and / or other copyright owners and it is a condition of accessing these publications that users recognise and abide by the legal requirements associated with these rights.

\section{Take down policy}

The Research Portal is Ulster University's institutional repository that provides access to Ulster's research outputs. Every effort has been made to ensure that content in the Research Portal does not infringe any person's rights, or applicable UK laws. If you discover content in the Research Portal that you believe breaches copyright or violates any law, please contact pure-support@ulster.ac.uk. 


\section{Highlights}

- Commercial cartridge filters are effective in household water treatment systems.

- Upon cake formation, two pleated filters in series removed $100 \%$ of turbidity.

- Field trials with two spun filters in series reduced turbidity to $<1.2$ NTU.

- Source water particle size distribution determines turbidity removal efficiency.

- Cartridge filters' micron rating does not determine their pore sizes. 
Graphical abstract

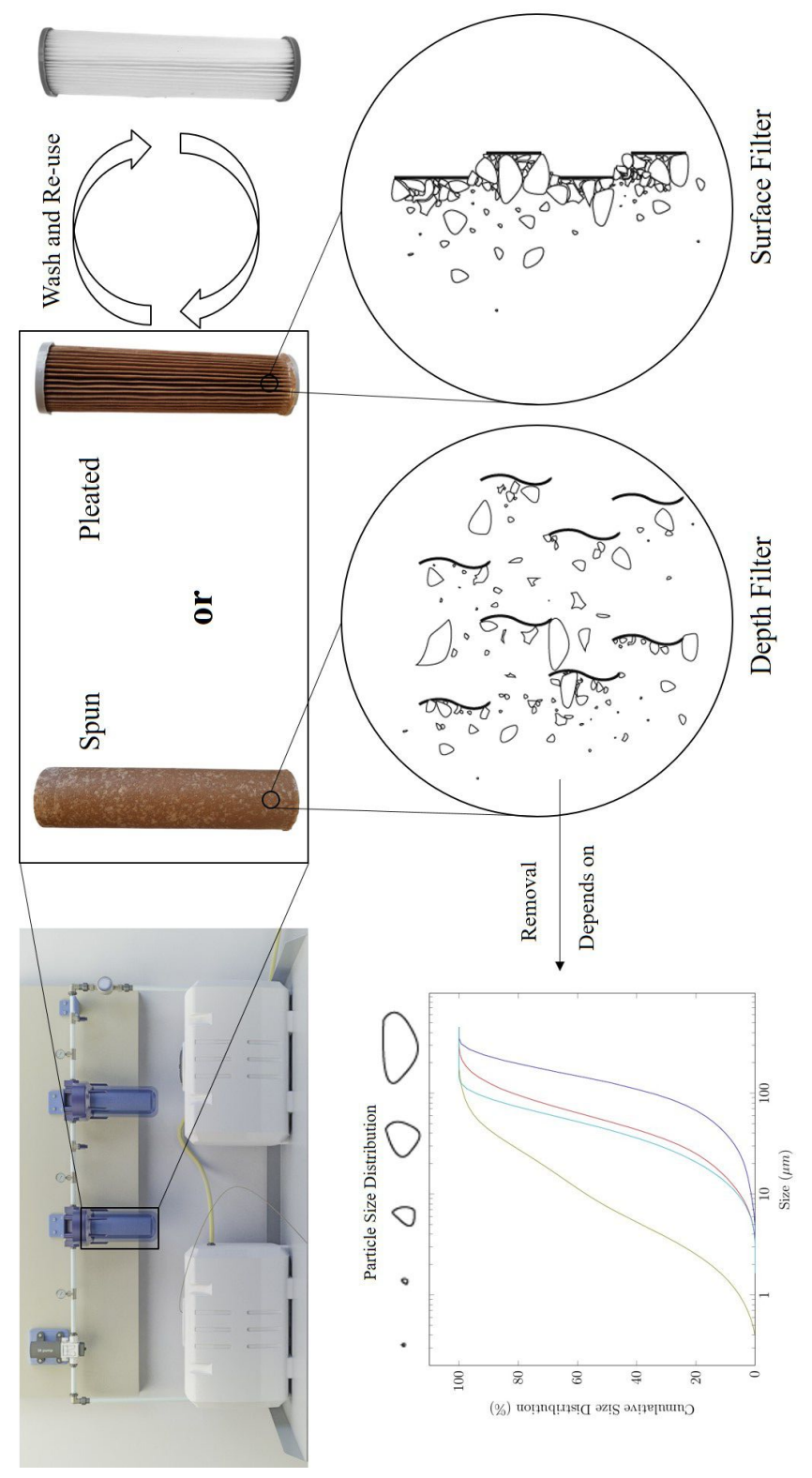




\title{
Assessment of low-cost cartridge filters for implementation in household drinking water treatment systems
}

\author{
Arsalan Afkhami ${ }^{a, *}$, Mattia Marotta ${ }^{\mathrm{b}}$, Dorian Dixon ${ }^{\mathrm{a}}$, Nigel G Ternan ${ }^{\mathrm{c}}$, \\ Luis Javier Montoya $^{\mathrm{d}}$, Margarita Hincapie ${ }^{\mathrm{d}}$, Laila Galeano ${ }^{\mathrm{d}}$, Pilar \\ Fernandez-Ibanez ${ }^{\mathrm{a}}$, Patrick S M Dunlop ${ }^{\mathrm{a}}$ \\ ${ }^{a}$ School of Engineering, Ulster University, Newtownabbey, Co. Antrim, UK \\ ${ }^{b}$ Department of Civil Engineering, University of Salerno, Fisciano SA, Italy \\ ${ }^{c}$ School of Biomedical Sciences, Ulster University, Coleraine, Londonderry, UK \\ ${ }^{d}$ School of Engineering, University of Medellin, Cra 87 No 30-65 Medellin 050026, \\ Colombia
}

\begin{abstract}
In regions where houses are sparsely located, traditional centralized water treatment plants are not economically feasible, and household water treatment (HWT) systems are commonly used to provide potable water for a range of household activities. Filtration prior to disinfection is essential, and due to their ease of use and small footprint, cartridge filters are commonly employed. In this work, readily available commercial filter types (spun, wound and pleated) of different micron ratings $(10,5$ and 1) were tested for the removal of turbidity either alone or in series in simulated large volume pilot trials. An initial turbidity of $40 \pm 10 \mathrm{NTU}$ was prepared using fine test dust (ISO 12103-1, A2) with the turbidity removal efficiency, pressure drop, total capacity and lifespan of the filters evaluated.

To increase the potential useable filter lifetime, upon reaching the 1 bar pressure limit, a series of washing steps were employed to regenerate the filters. Whilst pleated filters could be efficiently cleaned, spun and wound filters could not, and were discarded after single use. In pilot trials, the volume of turbid water filtered varied from $0.85 \mathrm{~m}^{3}$ with a 1 micron wound filter
\end{abstract}

\footnotetext{
*Corresponding author.

Email addresses: afkhami-a@ulster.ac.uk (Arsalan Afkhami), ars.svs@gmail.com (Arsalan Afkhami)
} 
to $6 \mathrm{~m}^{3}$, with 5 and 1 micron pleated filters in series, which could be used for three filtration cycles. For pleated filters, turbidity removal efficiency improved over time as a cake built up with the effluent turbidity reaching acceptable quality $(<5 \mathrm{NTU})$. This criteria continued to be achieved with repeated cycles of washed pleated filters, significantly reducing the cost and improving sustainability of the HWT system. Field trials were carried out with a similar HWT system configuration (5 and 1 micron spun filters) in HWT systems installed in households of rural communities in Curiti, Colombia. Turbidity was effectively removed from natural water (reduction to $<$ $1.2 \mathrm{NTU}$ ) with improved efficacy in comparison to synthetic samples due to the large particle size distribution observed in the natural water.

Keywords:

Low-cost filtration, Cartridge filter, Turbidity removal, Household water treatment, Micron rating

\section{Introduction}

Universal and equitable access to safe and affordable drinking water for all by 2030 is Target 6.1 of the UN Sustainable Development Goals (SGDs) [1]. According to the latest WHO report in 2017, 844 million people lacked access to an improved water source located in their proximity, and even if this was available, 27 percent of water sources were not free from contamination. Furthermore, this information is based on water quality estimates for only $45 \%$ of the global population [2].

Turbidity, described as the scattering of light at 90 degrees from a reference beam, due to the presence of inorganic particles (clay and silt), chemical precipitates (manganese and iron), and organic particles (organisms and plant debris) is often used as a simple indicator of water quality with presence assumed to equate to contamination. It can be measured easily, quickly and reliably by a variety of devices including the low-cost, portable turbidity tubes. Turbidity is also a recommended measurement for water quality in the WHO's 'Guidelines for Drinking-water Quality' [3].

Turbidity can reduce the effectiveness of disinfection treatments, such as UVC radiation, causing shielding of microorganisms from the radiation. Turbidity is commonly expressed in Nephelometric Turbidity Units (NTU); values above 4 NTU would visibly affect the aesthetics of water and from a treatment perspective, increase the UV dose requirement and the residence time 
required to guarantee the absence of pathogens in the treated water. Consumers often associate low turbidity with safe drinking water despite the fact that turbidity in itself does not always represent a risk [3-8]. However, with respect to water treatment, removal of turbidity is an important efficiency measurement for physical filtration based systems [9].

Filtration is considered the most practical and affordable process to remove turbidity and suspended particles for drinking water applications. Cartridge filtration is suitable for small volume applications, which consists of a single (or multiple) filter element(s) inside a low cost housing. These filters do not require specialist knowledge in relation to operation and maintenance [1012], while providing a one-step separation process without the need for prior coagulation and flocculation, considered as an essential step in conventional water treatment [13]. However, cartridge filters need to be discarded when the pressure drop exceeds the operating range. These filters are commonly made of polypropylene or polyester with commercial cartridge filter types being wound, spun (meltblown) and pleated [14, 15].

With respect to removal of particles, filtration can be categorized into two types (a) depth filtration and (b) surface/cake filtration, depending on where the filtered solid is located. In depth filters (Figure 1a), particles are removed throughout the depth of the medium. In this type of filtration, particles of diameters smaller than the filter's pore size can be removed in a two-step process of transport (advection) and attachment via different deposition mechanisms, namely, inertial impaction, gravity (only in gravitational flows), interception, and Brownian diffusion. In surface filtration (Figure 1b), particles of larger diameter than the filter's pore size are strained and form an external filter cake, which improves the filtration efficiency as the cake itself acts as a depth filter [10, 16-18]. By this definition, spun and wound filter elements are classified as depth filters and pleated filter elements are surface filters.

Given the need for provision of safe water for a range of household level applications, in addition solely to consumption, the UN and WHO recommend the amount of safe drinking water required for one person per day may vary from 20 to 50 litres [19], depending on the climate and geographic area. Therefore, with system output of $250 \mathrm{~L}$ per day for a family of 5 members; the implementation of conventional treatment methods such as slow sand filtration [7, 20], rapid sand filtration [8], or ceramic filtration [21, 22] which require high installation costs and long treatment times would not be appropriate.

Although cartridge filters are commonly used in domestic water treatment 


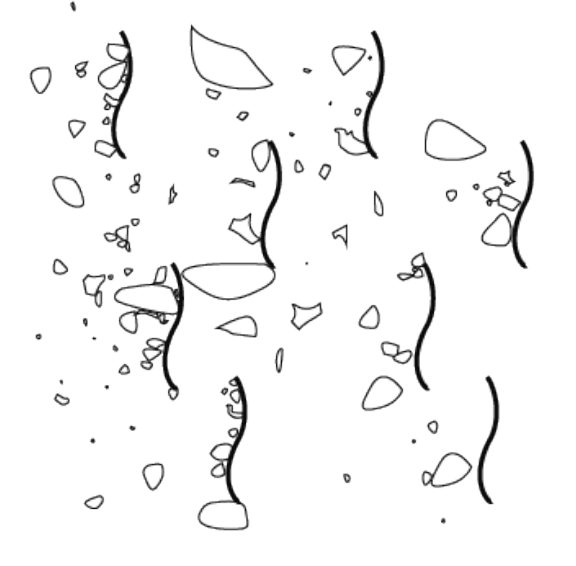

(a)

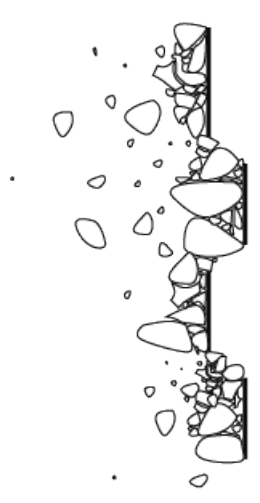

(b)

Figure 1: Two main categories of filtration: (a) depth filtration and (b) cake filtration.

systems, very few studies focus on measuring the efficiency of such system specifically for drinking water treatment [23], with research mostly focused on air pollution [18]. Moreover, filter manufacturing companies report only the micron rating, pressure drop in clean filters and the Beta ratio in product literature, they do not test their filters under conditions of turbid water suspensions in accordance with the protocol of the WHO 'International Scheme to Evaluate Household Water Treatment Technologies' [24] nor investigate the long-term performance of their products.

The nominal micron rating reported by manufacturers is only a rough indicator of the particle size that might be removed by the filter medium as this corresponds to the particle size which the filters may retain - therefore, in practice two filters with the same micron rating can have differing performances. Instead, the Beta ratio is recommended by the Filter Manufacturers Council as a suitable filtration comparison parameter [25]. However, the Beta ratio ignores particles smaller than a filter's micron rating. Therefore, when using A2 fine test dust as the turbidity agent, even if a high Beta ratio is achieved by a 1 micron filter, low turbidity reduction might be observed given turbidity is number dependent [26] and $82 \%$ of A2 fine test dust particles are 
smaller than $1 \mu \mathrm{m}$. This loose characterization also relies on close quality control during manufacture; however, the only performance related information available for low-cost commercial cartridge filters is the nominal micron rating.

Published academic works on cartridge filtration for water treatment do not provide the comprehensive information required to develop a HWT system, with only either hydraulic performance $[23,27]$ or removal of a specific contaminant [28] investigated. Recently, Sikorska et al. [14] investigated both pressure drop and turbidity removal, using a tailor-made filter with six layers, which is a new approach.

The aim of this paper is to undertake a systematic investigation of the performance of several commercial and commonly used cartridge filter elements, i.e. spun, wound and pleated, of different micron ratings with turbid water according to the WHO HWT testing scheme [24]. Turbidity removal, pressure drop and cleaning steps permitting filter reuse were evaluated to determine the most appropriate choice of a cartridge filter in regards to production of water with a consistent turbidity below $5 \mathrm{NTU}$ - as recommended by WHO's 'Guidelines for Drinking-water Quality' [9].

\section{Materials and Methods}

\subsection{Instrumentation}

\subsubsection{Pilot tests}

A portable meter (Hanna Instruments, HI-93703) was used to measure the turbidity of water samples. A Scanning Electron Microscope (JEOL, JSM-6010) was used to take detailed images of test dust particles and fibers of the filters.

\subsubsection{Field tests}

A portable meter (HACH 2100Q) was used to measure the turbidity of water samples taken in the field. A particle size analyser (Mastersizer 2000, Malvern Panalytical) was used to measure the particle size distribution (PSD) of water samples from houses in Curiti.

\subsection{Preparation of turbid challenge water}

Fine test dust (ISO 12103-1, A2, Powder Technology Inc.), a red brown insoluble mineral composed mainly of silica with a density of $2500-2700$ $\mathrm{kg} / \mathrm{m}^{3}$, was used to prepare turbid water, based on the recommendations of 
the WHO scheme for evaluating HWT technologies [24]. The same grade of test dust is used in ISO 4572:1981, 'Hydraulic fluid power - Filters - Multipass method for evaluating filtration performance' [29], while the updated version, ISO 16889:2008, requires the use of ISO 12103-1, A3 medium test dust [30]. The subtle change in test dust parameters have been reported to not affect the actual performance of a wide range of filters [31]. Particle size distribution (PSD) by volume was provided by the manufacturer, and equivalent PSD by number presented in Figure 2. A2 test dust particles were mostly smaller than $1 \mu \mathrm{m}$ by number distribution, with the mean diameter of $0.779 \mu \mathrm{m}$, while the mean diameter by volume was much larger at 16.99 $\mu \mathrm{m}$. Moreover, an SEM image of sample particles (Figure 3) confirms the polydisperse nature of the test dust particles. Experimental measurements showed a linear correlation $\left(\mathrm{R}^{2}=0.97\right)$ between test dust concentration and turbidity with a slope coefficient of 0.68 and intercept set at 0 (Figure S1). This correlation was used to produce water-test dust suspensions achieving a specific turbidity.

The initial turbidity of the feed tank was controlled to be $40 \pm 10 \mathrm{NTU}$, in keeping with the WHO HWT systems challenge water criteria [24], using the correlation described above with confirmation by manual assessment. An additional trial with an initial turbidity of $120 \pm 10 \mathrm{NTU}$ was performed to investigate a potential worst case scenario as well as the effect of very high inlet turbidity on filtration cycle duration when pleated filters were used.

In addition, two trials were performed with kaolin clay (Sigma-Aldrich) which has a different PSD to test dust (Figure S2). The concentration of the kaolin added was the same as the test dust, $60 \mathrm{mg} / \mathrm{L}$, with the correlation of the kaolin concentration and turbidity given in Figure S1.

\subsection{Experimental Set-up}

\subsubsection{Pilot tests}

A drawing of the test system used is shown in Figure 4, comprising two 10 inch standard filter housings, suitable for Double Open End (DOE) filter elements. Belfast tap water (Antrim, UK) was fed into the inlet tank by a hose, and the water level kept constant by a float valve. A concentrated test dust stock was prepared by adding $34 \mathrm{~g}$ of A2 fine test dust to $3 \mathrm{~L}$ of tap water, which was dosed at $28.8 \mathrm{~mL} / \mathrm{min}$ to the feed tank by a peristaltic pump (101U, Watson Marlow) ensuring a concentration of $60 \mathrm{mg} / \mathrm{L}$ and a turbidity of $40 \pm 10 \mathrm{NTU}$. To achieve $120 \mathrm{NTU}$ for one of the trials, $102 \mathrm{~g}$ of test dust was used in $3 \mathrm{~L}$. Particles in the stock were kept fully suspended 


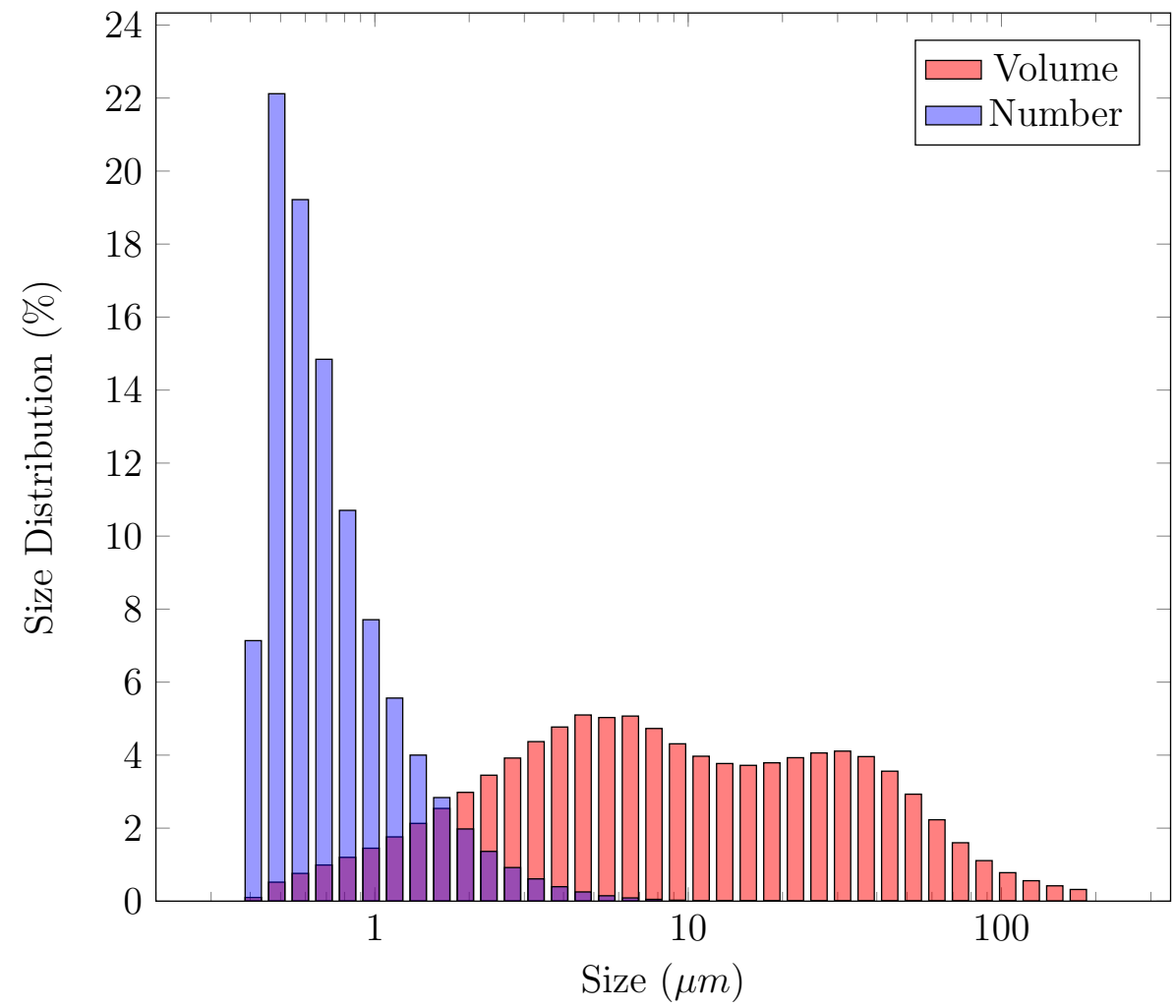

Figure 2: Volume and number particle size distribution (PSD) of A2 fine test dust used in the trials (calculated using data provided by Powder Technology Inc.). 


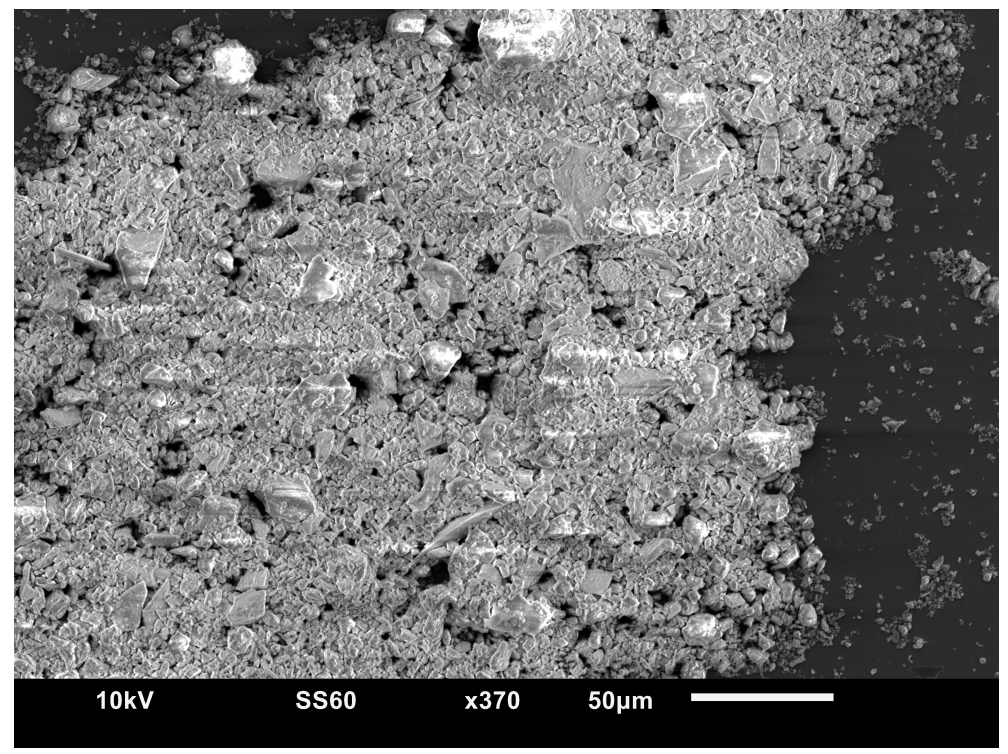

Figure 3: An SEM image of A2 fine test dust particles used in the trials.

during the trials using a magnetic stirrer at $100 \mathrm{rpm}$. An aquarium pump (Intercept, PF Mini) was utilized to internally recirculate the inlet tank suspension preventing settlement of larger particles inside the tank. A small 12V DC on-demand pump (Shurflo, Model 2095-204-412) was used as the main feed pump for the filtration system. This pump was chosen because it is suitable for household use, being wall mountable with a low noise level (50 $\mathrm{dB}$ measured by a mobile application at a distance of $10 \mathrm{~cm}$ ). The pump had a maximum operating pressure of 1.6 bar, and during the filtration trials, the initial flow rate of $5.2 \mathrm{~L} / \mathrm{min}$ decreased to $4.4 \mathrm{~L} / \mathrm{min}$ as the pressure increased to 1 bar (both flow rate and pressure were variable). Each filter assessment trial consisted of several runs spanning days or weeks in duration with a test volume for each run being $0.5 \mathrm{~m}^{3}$. Following processing of 50 or $100 \mathrm{~L}$, samples $(50 \mathrm{~mL})$ were taken from the feed tank and the sampling valves after each filter. Samples were shaken before measurement of turbidity in order to avoid underestimation of turbidity due to settled particles. Each sample was measured three times and the average calculated.

The commercial filters used in this study were obtained from three UK distributors (Finerfilters Ltd., Aqua Cure Ltd. and The Water Filter Men), details are presented in Table 1 . Filters with a similar technical parame- 


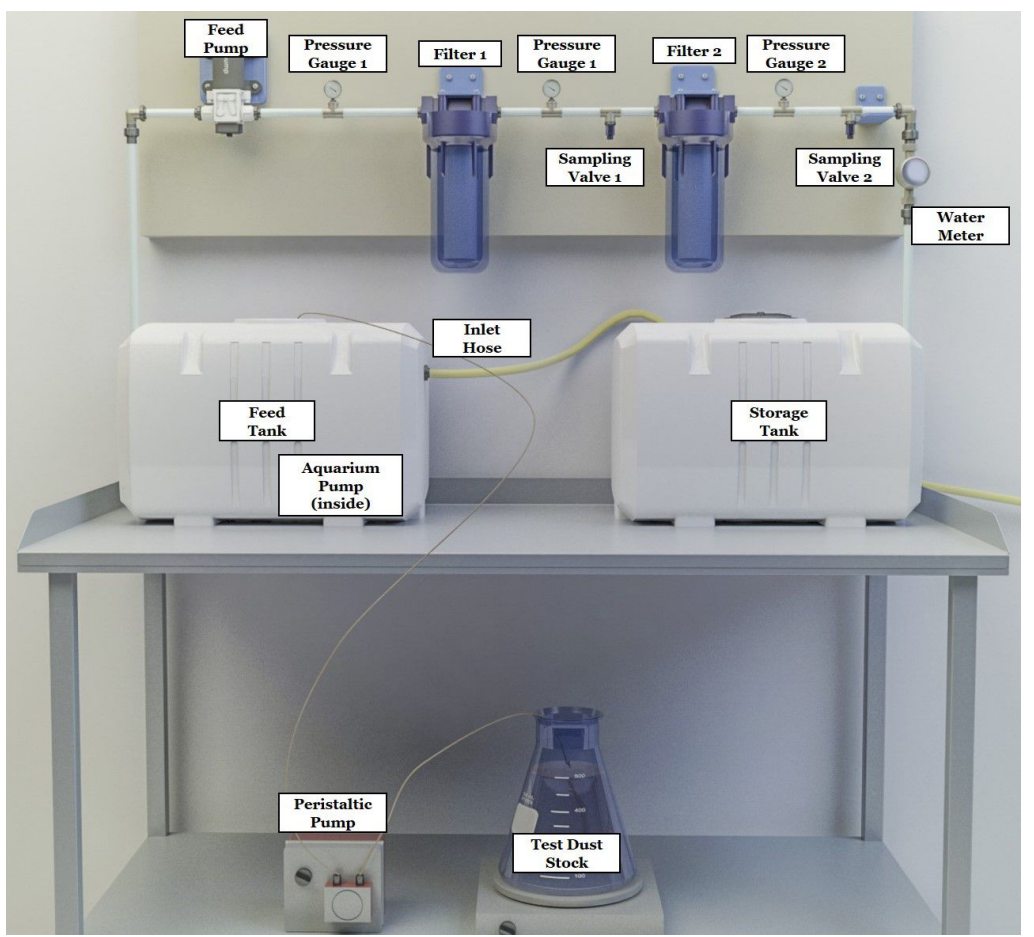

Figure 4: A drawing of the test system used for testing the commercial cartridge filters. 
ters can be readily found in other countries from a range of suppliers. The spun and wound filters were made of polypropylene and pleated filters from polyester. As different filter elements were used in the trials, the following notation was used to describe the filter type ('S' for spun, ' $\mathrm{P}$ ' for pleated and ' $W$ ' for wound) with the subsequent number referring to the micron rating. If two in-line filters were used (i.e two filters in series), a '+' sign is shown, e.g. $\mathrm{S} 10+\mathrm{S} 1$ represents a 10 micron spun filter (Filter 1 in Figure 4) followed by a 1 micron spun filter (Filter 2 in Figure 4). In addition, a 10 inch ceramic cartridge filter and a 10 inch cartridge sand filter were also prepared; however, due to a high initial pressure drop $(\Delta \mathrm{P})>1$ bar, turbidity removal trials were not performed. Filter elements with micron ratings of 10,5 and 1 micron were trialled.

Table 1: Cartridge filter elements used in this study

\begin{tabular}{llll}
\hline Abbreviation & Filter Type & Micron Rating & Manufacturer/Supplier \\
\hline S10 & Spun & 10 & SPECTRUM \\
S5 & Spun & 5 & Finerfilters Ltd. \\
S1 & Spun & 1 & Finerfilters Ltd. \\
W5 & Wound & 5 & Aquafilter \\
W1 & Wound & 1 & Aquafilter, The Water Filter Men \\
P5 & Pleated & 5 & The Water Filter Men \\
P1 & Pleated & 1 & The Water Filter Men \\
- & Ceramic $^{*}$ & - & The Water Filter Men \\
- & Sand $^{*}$ & - & The Water Filter Men \\
\hline
\end{tabular}

* not trailed due to high pressure drop.

Three analogue pressure gauges were used to measure pressure drop after each filter, and a water meter (Ferro) was included to measure cumulative treated water volume and flow rate (by measuring time). Most trials were stopped when the initial pressure gauge reached 1 bar, due to leakage of influent into the outlet at high pressures in DOE filter housings. Moreover, the pump used in this HWT system provided a maximum pressure of 1.6 - 1.8 bar, and considering an extra static head required for piping in the field and the required elevation of a storage tank, 1 bar was considered the maximum available head for the filtration system.

Potential to wash and reuse filter elements was assessed following achievement of the 1 bar pressure limit. Pleated filters were cleaned simply by running 
under a tap, shaking in a housing full of water for $3-5$ minutes and if any cake was still attached, it was gently removed by hand. After cleaning, some cake remained on the folds, and particles were observed to be entrapped in the filter medium, these were not removed. Cleaning and reuse of spun and wound filters was not possible as particles were entrapped in the filter medium, as such they were discarded after single use.

\subsubsection{Field tests}

Field based assessment of the HWT system was undertaken in Curiti (Liborina), Colombia (Figure 5). The inlet tank was filled with untreated water from a house in the village via a hose. A $0.5 \mathrm{hp}$ centrifugal pump (Evans, model BP1ME050) was used to feed the filtration system consisting of two standard 10 inch filter housings. Spun filters (PURIKOR, Colombia) were used for the field test with ratings of 10,5 and 1 micron. Two sets of filters $\mathrm{S} 10+\mathrm{S} 1$ and $\mathrm{S} 5+\mathrm{S} 1$ were trialled in each house. Three samples were taken, from the influent and the effluent valves at each filter at $0,0.12$ and $0.25 \mathrm{~m}^{3}$. Subsequently, turbidity was measured in triplicate and the average calculated.

During the tests, the pump operated within a pressure range of $1-3.5$ bar with a flow rate of $4 \mathrm{~L} / \mathrm{min}$. Each filter evaluation test consisted of several one-hour runs in two houses and at one central storage tank in Curiti in Colombia. The test volume for each run was $0.25 \mathrm{~m}^{3}$.

\section{Results and discussion}

\subsection{Pilot tests}

Images of the spun, wound and pleated filters ( 5 micron) prior to use (clean) are shown in Figure 6a. A slice was physically removed from each filter and imaged with SEM (Figure 7). It was observed that spun filters are constructed of many layers of fibers each of different diameters (1.1 $34.3 \mu \mathrm{m}$ ) arranged in random orientation (Figure 7a). Whilst there was no noticeable difference between the pore size within filters of different micron ratings (SEM images in Figure S3), spun filters with lower micron rating had more compact layers of fibers. Fibers in pleated filters (Figure $7 \mathrm{~b}$ ) were randomly oriented with a uniform diameter distribution $(14.23 \pm 2.15 \mu \mathrm{m})$. Pleated filters of different micron ratings, show no significant variability in the pore structure (Figure S4), only the thickness of the filter media (mat) was different. Figure $7 \mathrm{c}$ shows the wound filter structure as a single yarn, 


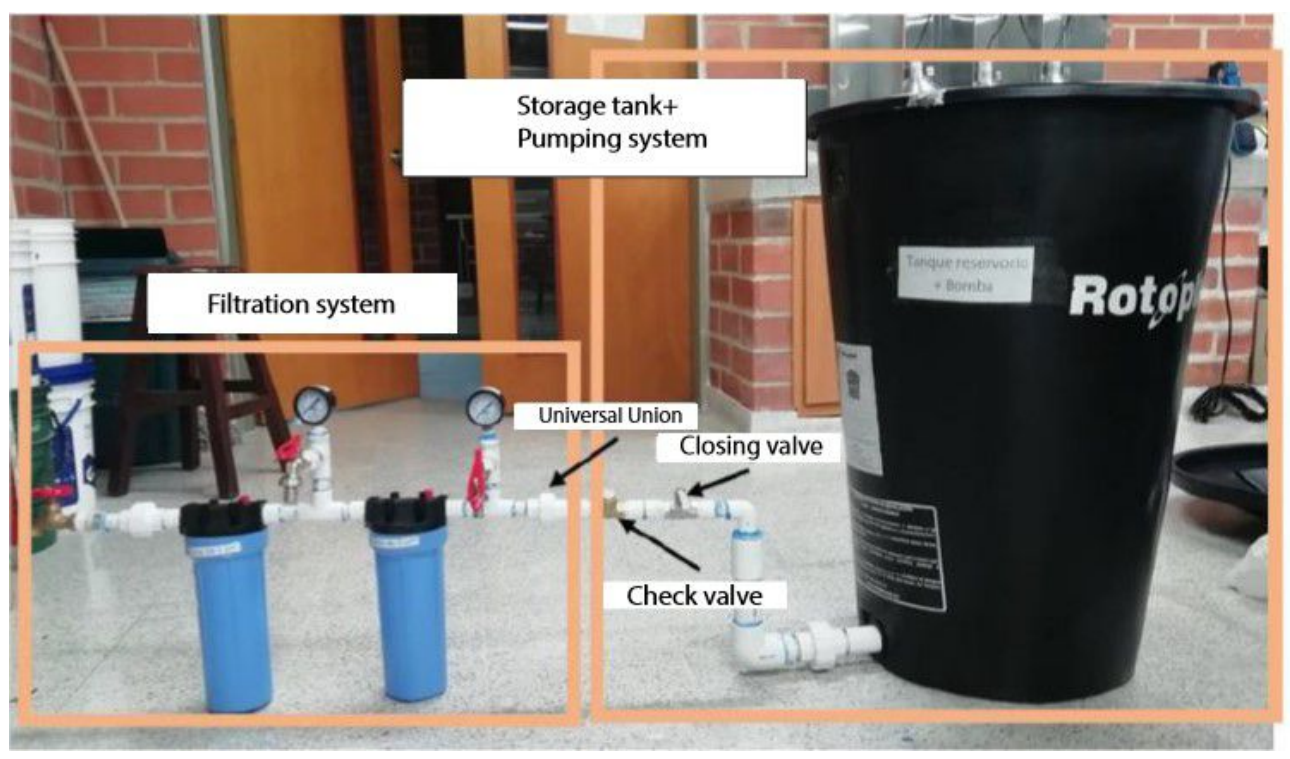

Figure 5: The system used for the field tests in Liborina, Colombia.

diameter of approximately $2 \mathrm{~mm}$. The fibers are somewhat aligned with diameter varying from $30.29 \pm 10.01 \mu \mathrm{m}$. However, the gaps between yarns are larger than the internal gaps between the wound filter fibers shown in Figure 7c. It was observed that wound filters of different micron rating had yarns of different diameters, e.g. $1.4 \mathrm{~mm}$ for 1 micron filter (Figure S5), which affects the size of the gap between the yarns, and hence the size of particles that are removed.

During the initial stages of filtration, it was observed that particles deposit randomly on the middle and lower regions of the filter elements, due to the flow path inside the housing. As the permeability of these regions decreased, particles then deposited onto regions above with less resistance to flow - until the entire filter became 'dirty' (Figure 6b).

In the first trials, $\mathrm{S} 10+\mathrm{S} 5$ and $\mathrm{S} 5+\mathrm{S} 1$ filters were used, respectively (Figure 8). To ensure clarity, trend lines obtained via fitting the experimental results to a linear model have been included. It was observed that despite the smaller micron ratings of $\mathrm{S} 5+\mathrm{S} 1$, turbidity reduction after the 2 nd filter does not show any improvement and does not reach the target $<5$ NTU. In S10 + S5, an improved reduction was observed only after a flow volume of between 0.9 and $1.2 \mathrm{~m}^{3}$, which corresponds to the sudden pressure increase 

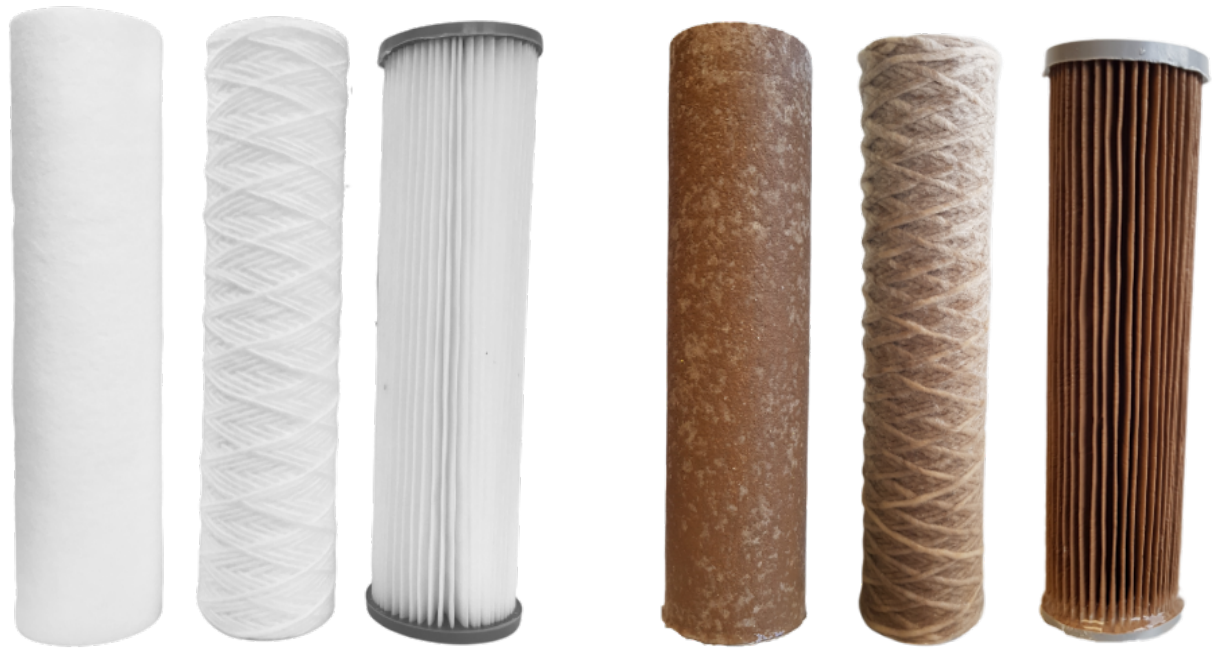

(a) Clean

(b) Dirty

Figure 6: The three types of cartridge filter elements used in this study: spun (left), wound (middle) and pleated (right).

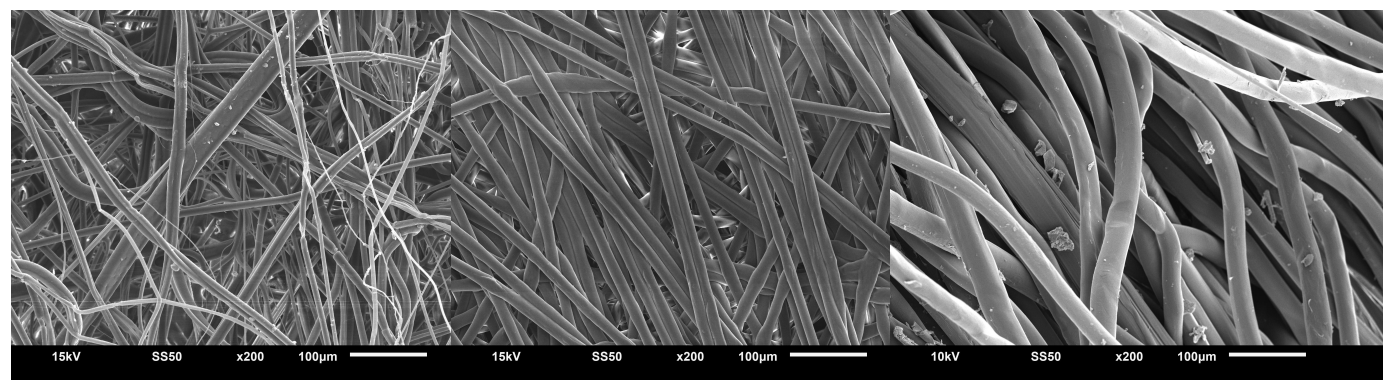

(a)

(b)

(c)

Figure 7: SEM images of a cross-section of cartridge filters used in this study: (a) 5 micron spun, (b) 5 micron pleated and (c) 5 micron wound filters. 
due to clogging (Figure 10). The next day, when a new run was started with the same filter, it was observed that particles were detached as the outlet water became cloudy, hence, increasing the turbidity and delaying the increase in $\Delta \mathrm{P}$ (pressure drop). In the $\mathrm{S} 10+\mathrm{S} 5$ trial, the observed lagging change in $\Delta \mathrm{P}$ after the total gauge pressure reached 1 bar was thought to be due to leakage which also corresponds with the lack of improvement in turbidity reduction.

In order to investigate whether the difference in filters' micron ratings (5 versus 1 micron) would alter turbidity removal efficiency, additional trials (Figure S6) were performed with kaolinite and two spun filters with the same micron ratings in series $(\mathrm{S} 5+\mathrm{S} 5$ and $\mathrm{S} 1+\mathrm{S} 1)$. Although kaolinite particles are finer than the test dust (Figure S2) and based on volume distribution $\approx 60 \%$ of particles are smaller than $5 \mu \mathrm{m}$ and $\approx 18.5 \%$ smaller than $1 \mu \mathrm{m}$, the difference in removal efficiency between the two filter set-ups was small $(\approx 10 \%)$. In almost a third of measurements, the total removal via S5 + S5 was higher than $\mathrm{S} 1+\mathrm{S} 1$ and in almost half of the turbidity measurements at the first filter, S5 had a higher removal percentage than S1. When either test dust or kaolin was used, the particles were much smaller than the pores, and they were not removed by straining, but rather by other deposition mechanisms (i.e. inertial impaction, interception and Brownian diffusion). This demonstrates that relying only on a filter's nominal micron rating as an indicator of removal efficiency was not sufficient and that the pilot testing was essential to inform accurate filter choice.

Trials with wound filter elements used the smallest micron ratings available on the market, W5 + W1 and W1 (single filter trial). Data in Figure 9 shows poor turbidity removal efficiency, with effluent $>20$ NTU frequently exiting the $\mathrm{W} 5+\mathrm{W} 1$ system during that trial, the $\Delta \mathrm{P}$ started to increase in the 1st filter after $1.4 \mathrm{~m}^{3}$, while $\Delta \mathrm{P}$ in the 2 nd filter remained constant until $1.9 \mathrm{~m}^{3}$ (Figure 10). In the trial of $\mathrm{W} 1$, the outlet turbidity approached zero as more particles were retained by the filter, and the $\Delta \mathrm{P}$ increased accordingly.

The benefit of two filters in series against a single filter became clear as the 1 micron filter operating alone clogged quickly requiring replacement after only $0.85 \mathrm{~m}^{3}$. The second filter is effectively 'protected' by the first filter from the volume of large particles that are primarily responsible for clogging.

Of the depth filters examined, only the trial using W1 reached the acceptable threshold of $<5 \mathrm{NTU}$ (according to the WHO [9]), but a rapid increase in pressure was observed with a volume of $<1 \mathrm{~m}^{3}$ treated (Figure 10). In trial 


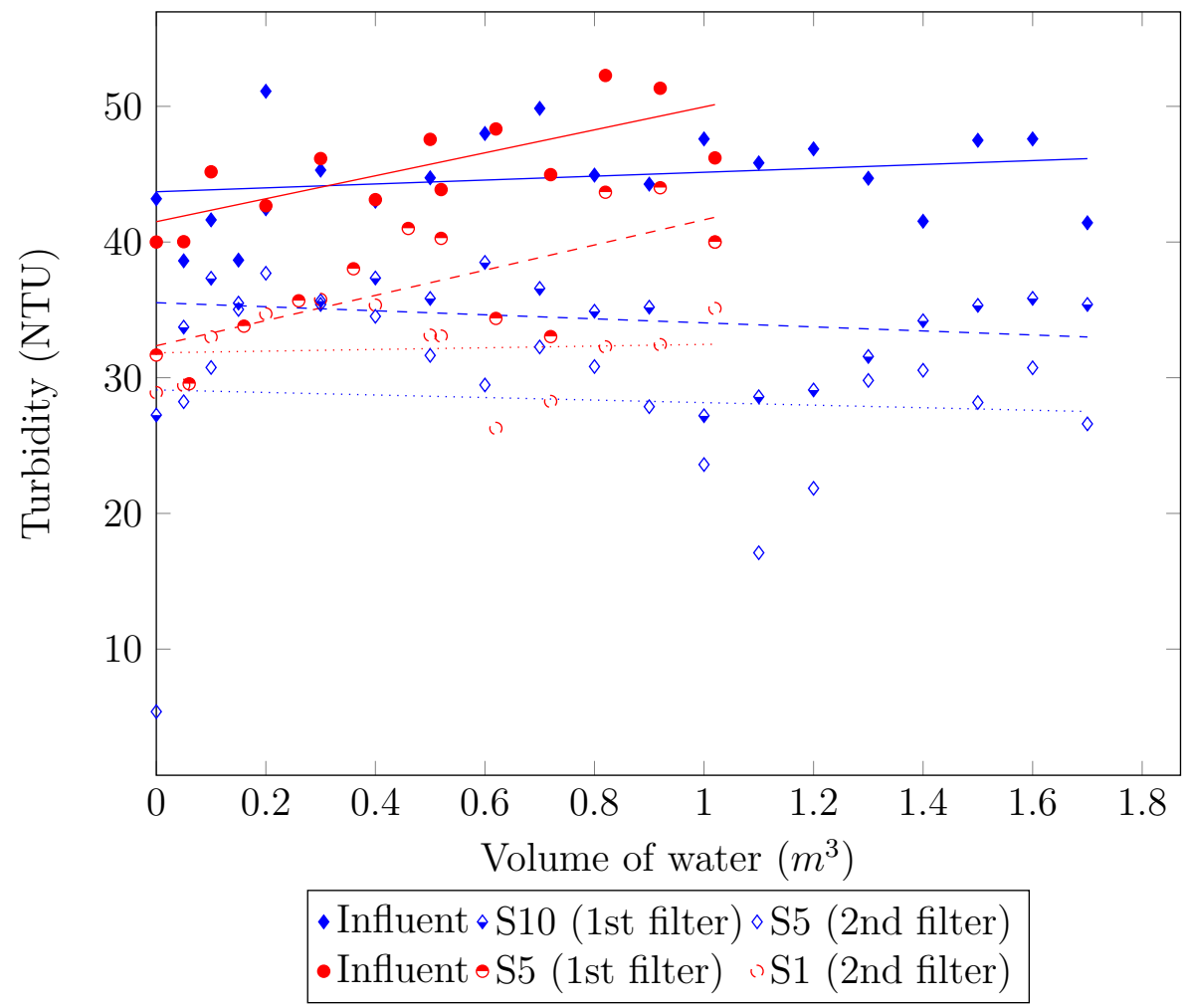

Figure 8: Turbidity measurements of influent and effluent of spun filters against the volume of water treated. S10 + S5 two spun filter elements (10 and 5 micron) in series, S5 + S1 two spun filter elements ( 5 and 1 micron) in series. 


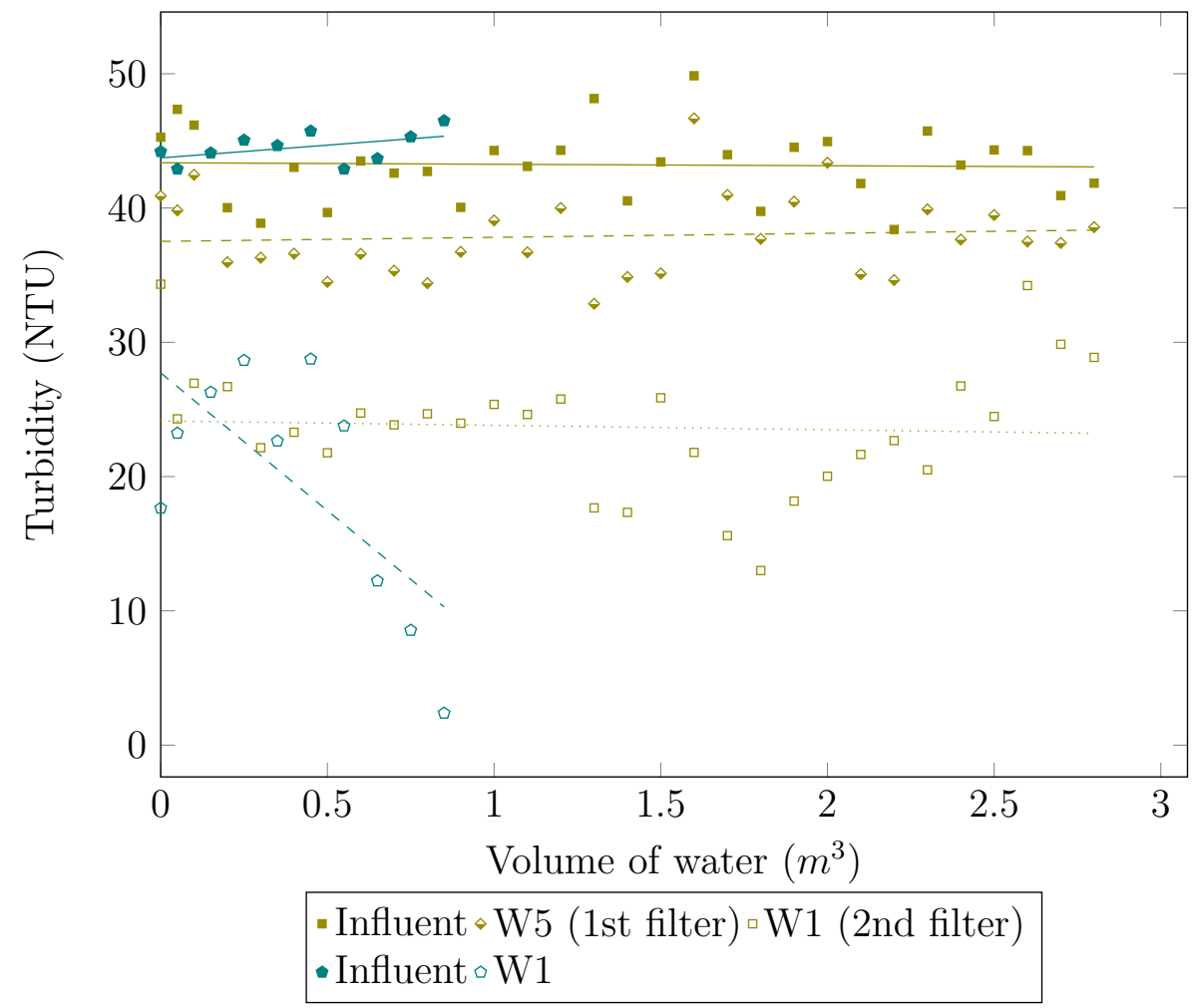

Figure 9: Turbidity measurements of influent and effluent of wound filters against the volume of water treated. W5 $+\mathrm{W} 1$ two wound filter elements (5 and 1 micron) in series and $\mathrm{W} 1$ one wound filter element (1 micron). 


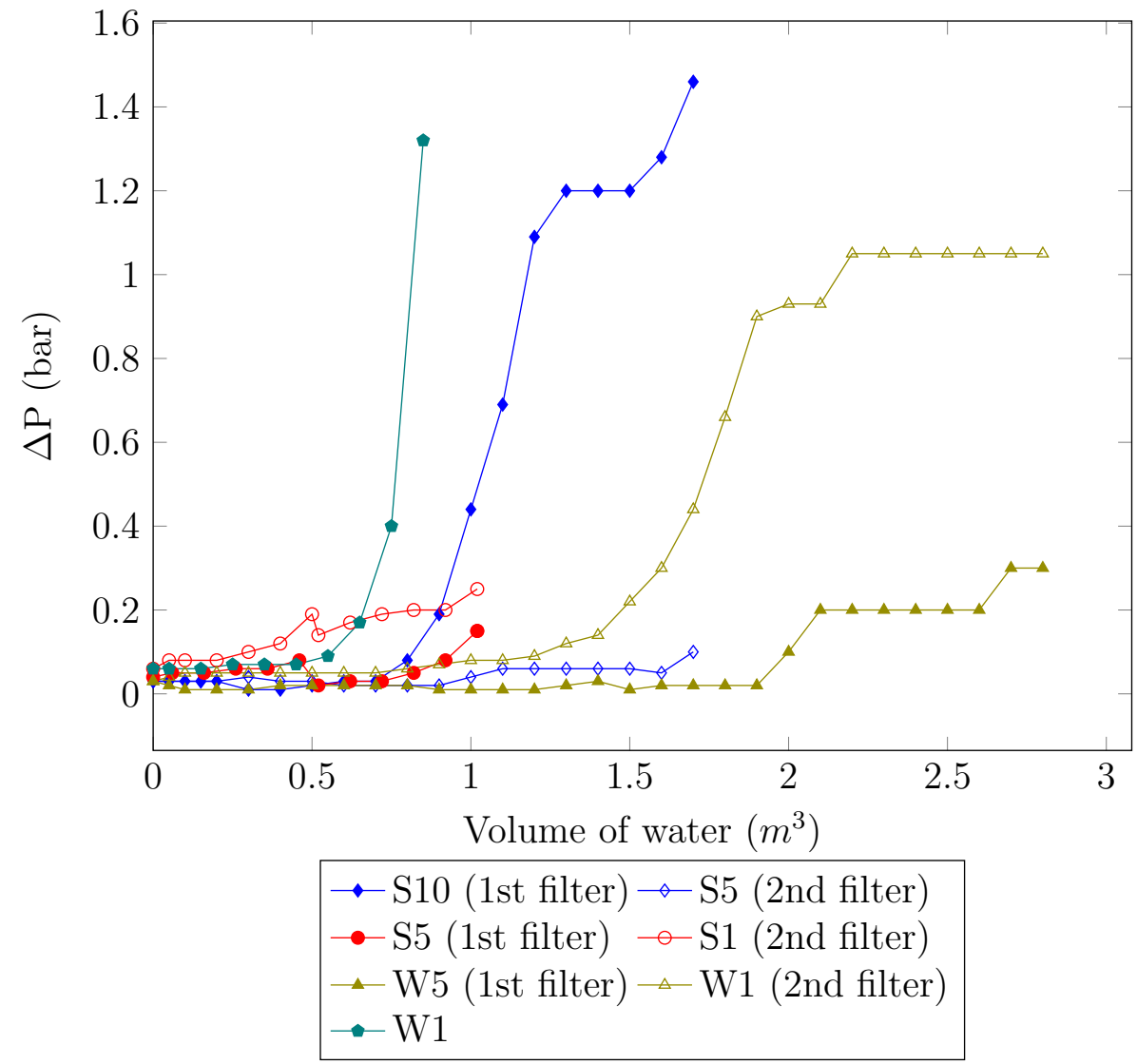

Figure 10: $\Delta \mathrm{P}$ measurements of each filter element against the volume of water treated. $\mathrm{S} 10+\mathrm{S} 5$ two spun filter elements (10 and 5 micron) in series, S5 + S1 two spun filter elements ( 5 and 1 micron) in series, W5 $+\mathrm{W} 1$ two wound filter elements ( 5 and 1 micron) in series and $\mathrm{W} 1$ one wound filter element (1 micron). 
$\mathrm{P} 5+\mathrm{P} 1,5$ and 1 micron pleated filters were tested in series (Figure 11) permitting direct comparison of micron rating with spun and wound filters. The final turbidity reached $<5 \mathrm{NTU}$ at a treated volume of $0.35 \mathrm{~m}^{3}$, which was further reduced to $0.00 \mathrm{NTU}$ after $0.65 \mathrm{~m}^{3}$. It can be observed that turbidity removal following the 1st filter improved as the pores were blocked by particles, effectively reducing the filter pore size. As the pressure increased, the turbidity removal declined, while the effluent turbidity of the 2nd filter remained constant upon reaching 0.00 NTU. As with the previous trials, a gauge pressure of 1 bar was considered the operational limit of this experimental set-up. It should be noted that the decline in $\Delta \mathrm{P}$ observed at intervals of approximately $0.5 \mathrm{~m}^{3}$, was due to the stop - start nature of the experimental runs. It was observed that when a run was stopped and housings were no longer pressurized; that some particles detached from the surface, dispersed in water, and settled on the bottom of the housing. Particles also settled in the filter housing during the runs, more so when the $\Delta \mathrm{P}$ increased and the fluid velocity decreased.

After washing, the cleaned pleated filters were placed back in the housings and used for another filtration cycle (Figure 11). In this 2nd cycle, turbidity reached $<5 \mathrm{NTU}$ after $0.3 \mathrm{~m}^{3}$ and $0.00 \mathrm{NTU}$ after $0.5 \mathrm{~m}^{3}$; due to more rapid development of cake on the filter resulting from the reduced porosity by entrapped particles from the initial cycle. Similarly, when washed and used in the 3rd cycle, turbidity reached $0.00 \mathrm{NTU}$ at $0.3 \mathrm{~m}^{3}$. However, the observed pattern of $\Delta \mathrm{P}$ during the three cycles was not the same (Figure 13). In the 1st cycle, the $\Delta \mathrm{P}$ of the 1 micron filter increase sharply after $0.65 \mathrm{~m}^{3}$, which corresponded to the same point that turbidity reached $0.00 \mathrm{NTU}$, while $\Delta \mathrm{P}$ of the 5 micron filter started to increase steadily but slowly initially (after $\left.0.35 \mathrm{~m}^{3}\right)$. In contrast, during the $2 \mathrm{nd}$ cycle, the $\Delta \mathrm{P}$ of the 1 st filter increased sharply after $0.4 \mathrm{~m}^{3}$. This effect was amplified during the 3rd cycle, with the $\Delta \mathrm{P}$ of the 1st filter increased sharply only after $0.2 \mathrm{~m}^{3}$, while the $\Delta \mathrm{P}$ of the 2nd filter was constant up to $0.7 \mathrm{~m}^{3}$ and increased slower than the previous cycle. In the 1st cycle, the open pores of the 1st filter permitted larger particles to pass, causing clogging in the 2nd filter; however, in the 2nd cycle, the size of pores of the 1st filter had been decreased due to the entrapped particles within the filter, resulting in the large particles being captured by the first filter during the 2nd cycle.

The observed $\Delta \mathrm{P}$ trend correlates well with turbidity removal, reaching 6.60 and $0.00 \mathrm{NTU}$ in the $2 \mathrm{nd}$ and 3rd cycles, respectively. As the volume of particles entrapped within the filter increased, the duration of each cycle (i.e. 
the volume of water processed prior to reaching the 1 bar limit) decreased from $2.35 \mathrm{~m}^{3}$ in the 1 st cycle to 2.07 and $1.53 \mathrm{~m}^{3}$ in the 2nd and 3rd cycles, respectively.

Assessment of P5 + P1 with an initial turbidity of $120 \pm 10$ was performed, lasting for three cycles processing 1.05, 1.2 and $1.05 \mathrm{~m}^{3}$ (Figure 11, red data points). It was observed that the turbidity of $<5 \mathrm{NTU}$ could be reached and filters could also be cleaned and reused effectively. Analysing the effluent turbidity results showed that despite the much higher concentration of particles in the influent, the formation of a uniform cake layer on the 2nd filter takes approximately the same volume of turbid water. This provides further evidence for the above concept relating to retention of only large particles within pristine filters, with the difference in the total volume of particles arriving to the 2nd filter irrespective of initial turbidity of either 40 or $120 \mathrm{NTU}$ being small. This is also reflected in $\Delta \mathrm{P}$ within the P5 + $\mathrm{P} 1$ trial at $120 \mathrm{NTU}$, pressure increased at a much faster rate than the trial with lower turbidity. Interestingly, in the 2nd cycle of the trial with P5 + $\mathrm{P} 1$ at high initial turbidity, although the 1st filter performed poorly, the effluent turbidity at the 2nd filter (1 micron) reached $0.00 \mathrm{NTU}$, which is also reflected in the filter's $\Delta \mathrm{P}$. Lower particle removal of the 1st filter during the 2nd cycle could be attributed to the very high volume of particles that reach the surface of the filter causing different cake structures or coverage in each cycle.

Comparing the volume of water processed in the 1st, 2nd and 3rd cycle of the 120 NTU experiment to the same cycle of the 40 NTU trial, we observe a reduction to $45 \%, 58 \%, 69 \%$, respectively. Expressed as a function of time rather than volume treated (Figure S7), a reduction to $52 \%, 56 \%$ and $60 \%$ was observed. We hypothesize that several factors are responsible for the lack of correlation, such as differences in the structure of the filter media and cleaning efficiency. Other factors might be related to the fluid flow field inside the housing as well as different particle-particle interaction at varying concentrations, which will be the topic of future research.

As with the single depth filter trial (W1), the performance of a single 1 micron pleated filter (P1) was examined to potentially reduce costs (housing, filter element and piping). As can be observed in Figure 12, turbidity decreased to $<5 \mathrm{NTU}$ after $0.45 \mathrm{~m}^{3}$ reaching a minimum of $1.53 \mathrm{NTU}$ at $0.55 \mathrm{~m}^{3}$. Turbidity removal subsequently decreased as $\Delta \mathrm{P}$ began to rise (Figure 14). An outlet turbidity of $26.65 \mathrm{NTU}$ was observed with a $\Delta \mathrm{P}$ of 0.6 bar after $3.1 \mathrm{~m}^{3}$. Following cleaning, a similar initial reduction of turbidity was observed in the 
2nd cycle, turbidity reached $<5 \mathrm{NTU}$ at $0.3 \mathrm{~m}^{3}$ and $0.00 \mathrm{NTU}$ at $0.4 \mathrm{~m}^{3}$, with subsequent decrease in particle removal resulting in a turbidity of $21.78 \mathrm{NTU}$ and pressure of 0.9 bar (at $3.1 \mathrm{~m}^{3}$ ). The observed trend for a single 1 micron filter was similar to the 1st filter of the two-filter trials - and we hypothesize that as the pores became smaller, turbidity removal improved; and as a result the pressure increased and the turbidity removal declined.

Comparing 5 and 1 micron filters when used as the 1st filter, it can be seen that in the initial cycles, the 5 micron filter reached a minimum effluent turbidity of $10.57 \mathrm{NTU}$ at $0.55 \mathrm{~m}^{3}$ with turbidity removal gradually decreasing to a value of $24.77 \mathrm{NTU}$ as the pressure reached 1 bar at $2.35 \mathrm{~m}^{3}$.

With the 1 micron filter, effluent turbidity of 1.53 NTU was observed at $0.55 \mathrm{~m}^{3}$ again the pressure increased resulting in turbidity removal falling to $20.5 \mathrm{NTU}$ at $2.35 \mathrm{~m}^{3}$ of processed water. Each cycle of the trial with P1 lasted for a larger volume than with $\mathrm{P} 5+\mathrm{P} 1$ because the removal efficiency was lower, hence less particles were accumulated in the cake. The pressure change resulting from the single filter is also likely to have an influence on the cake formation and filtration efficiency. As the criterion of an effluent turbidity of $<5 \mathrm{NTU}$ was only satisfied during a short period, the data confirms the need for multi-step filtration.

\subsection{Field tests}

A series of filtration tests were conducted with natural surface water from two houses and one central storage tank in Curiti (Liborina), using the system described in Figure 5. Natural water trials were conducted using S5 + $\mathrm{S} 1$ and $\mathrm{S} 10+\mathrm{S} 1$ filters at each location in two days. Data in Table 2 shows that turbidity was effectively reduced at the outlet to below the 5 NTU target; the low influent turbidity being a function of the season and associate water quality. Turbidity was effectively removed by the 1st filter (S5 or S10), in accordance with the PSD shown in Figure 15. The 2nd filter (S1) further removed particles achieving a final effluent of $<1.2 \mathrm{NTU}$ in all cases. Post-trial visual examination of the filters confirmed particle entrapment on the S5 and S10 filters (Figure 16) in a similar fashion to the lab based pilot experiments with the test dust.

Figure 15 shows the cumulative PSD of particles in the natural surface water in comparison to A2 test dust. The natural water contained a significantly greater proportion of large particles ( $50 \%$ of particles $>30 \mu \mathrm{m}$ ) than the test dust used in the above lab based pilot scale experiments. A2 test dust is pro- 


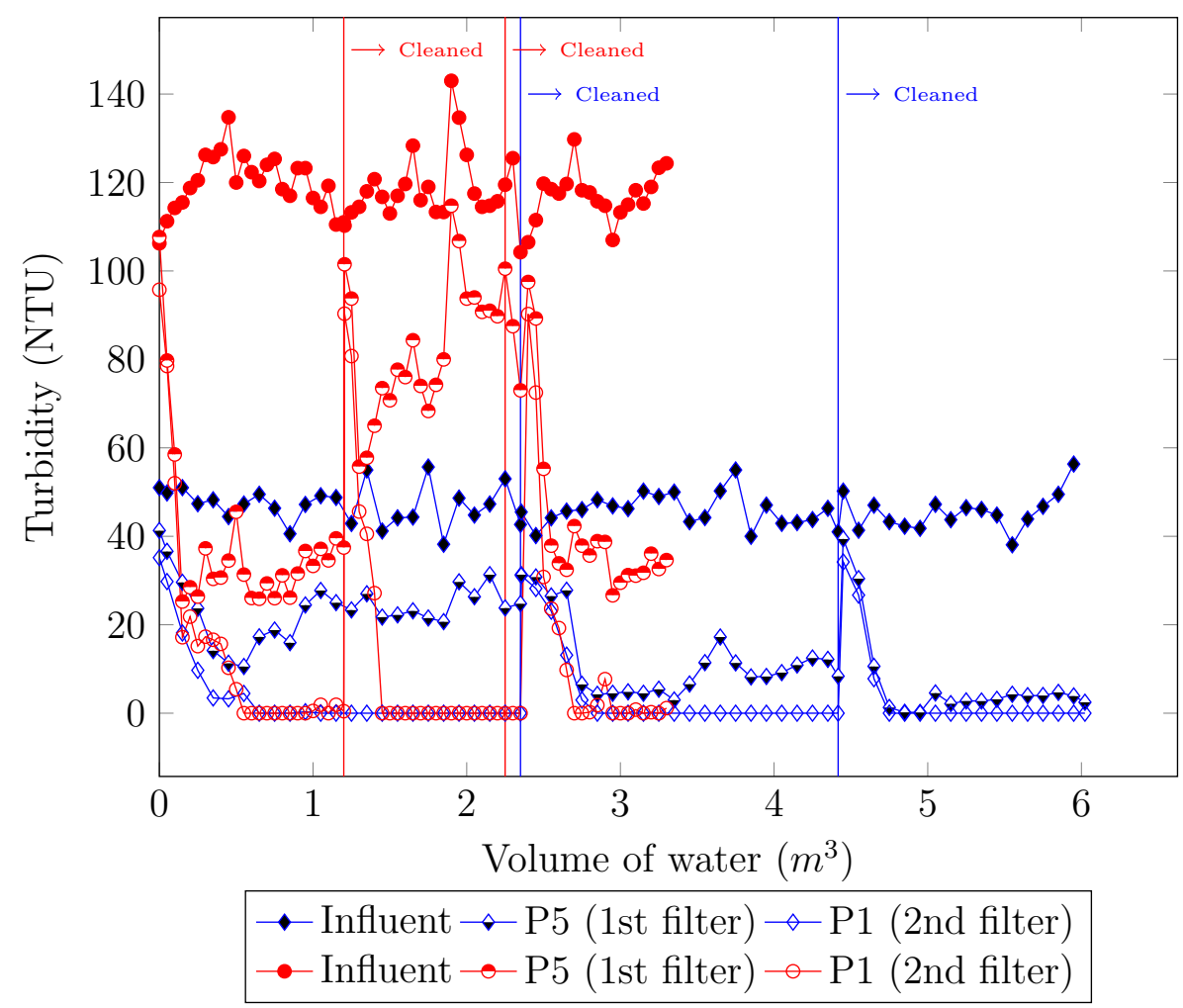

Figure 11: Turbidity measurements of influent and effluent of each pleated filter against the volume of water treated. P5 + P1 (blue) two pleated filter elements (5 and 1 micron) in series and intial turbidity of $40 \pm 10$ NTU, P5 + P1 (red) two pleated filter (5 and 1 micron) in series and initial turbidity of $120 \pm 10 \mathrm{NTU}$. 


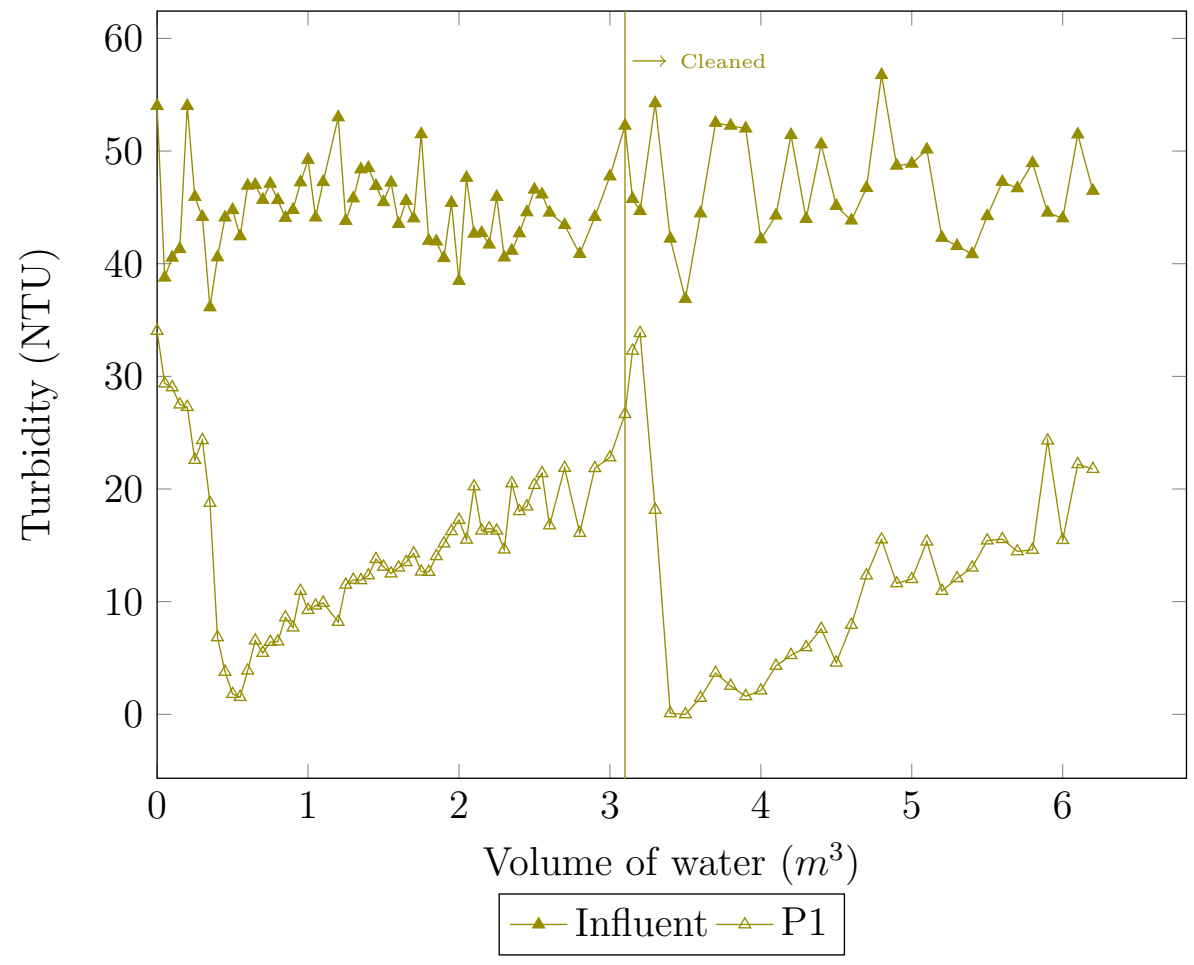

Figure 12: Turbidity measurements of influent and effluent against the volume of water treated of P1 a single pleated filter (1 micron) and initial turbidity of $40 \pm 10$ NTU. 


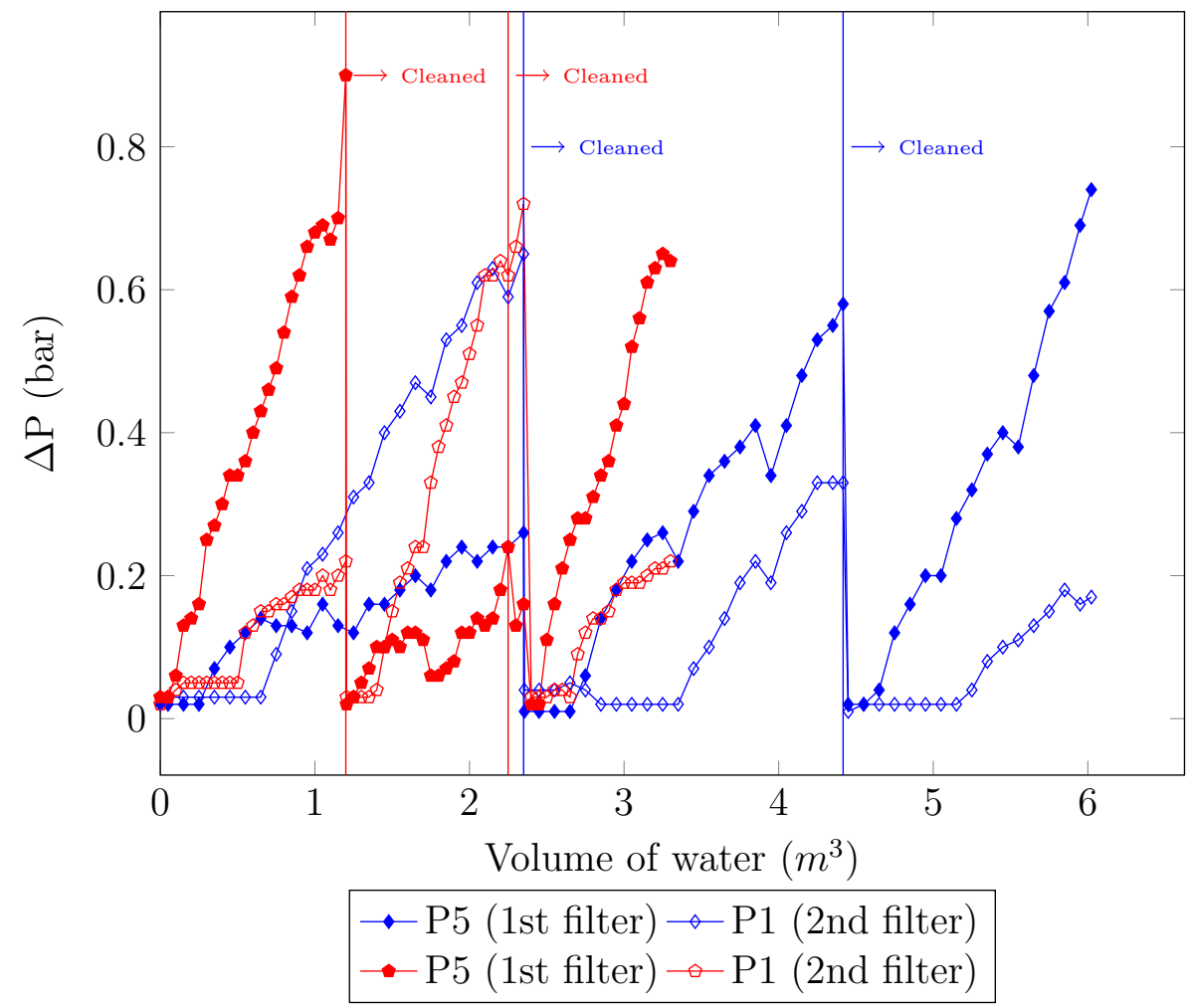

Figure 13: $\Delta \mathrm{P}$ measurements of each pleated filter element against the volume of water treated. P5 + P1 (blue) two pleated filter elements (5 and 1 micron) in series and intial turbidity of $40 \pm 10$ NTU, P5 + P1 (red) two pleated filter ( 5 and 1 micron) in series and initial turbidity of $120 \pm 10$ NTU. 


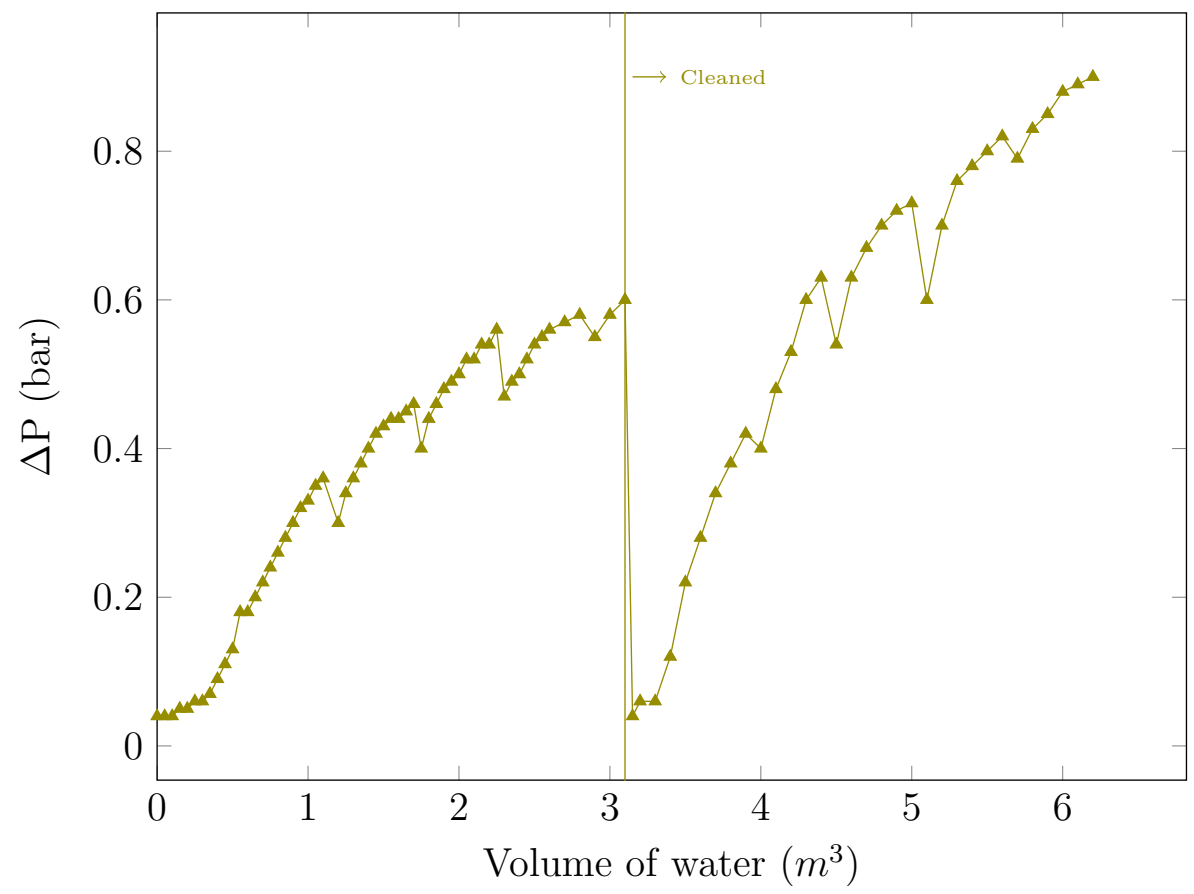

Figure 14: $\Delta \mathrm{P}$ measurements of $\mathrm{P} 1$ a single pleated filter (1 micron) and initial turbidity of $40 \pm 10 \mathrm{NTU}$. 
Table 2: Observed turbidity data in inflow and filtered water in the field.

\begin{tabular}{|c|c|c|c|c|c|}
\hline & Filters & $\begin{array}{c}\text { Volume } \\
\left(\mathrm{m}^{3}\right)\end{array}$ & $\begin{array}{l}\text { Inflow } \\
\text { (NTU) }\end{array}$ & $\begin{array}{c}\text { After S5 } \\
\text { (NTU) }\end{array}$ & $\begin{array}{c}\text { After S1 } \\
(\text { NTU })\end{array}$ \\
\hline \multirow[t]{3}{*}{ House 1} & \multirow[t]{3}{*}{$\mathrm{S} 5+\mathrm{S} 1$} & 0 & 11.8 & 1.38 & 0.6 \\
\hline & & 0.12 & 8.32 & 0.63 & 0.55 \\
\hline & & 0.25 & - & - & - \\
\hline \multirow[t]{3}{*}{ House 2} & \multirow{3}{*}{$\mathrm{S} 5+\mathrm{S} 1$} & 0 & 8.83 & 0.87 & 0.42 \\
\hline & & 0.12 & 8.18 & 2.23 & 0.49 \\
\hline & & 0.25 & 8.12 & 0.57 & 0.3 \\
\hline \multirow[t]{4}{*}{ Central tank } & \multirow[t]{3}{*}{$\mathrm{S} 5+\mathrm{S} 1$} & 0 & 6.38 & 5.8 & 1.01 \\
\hline & & 0.12 & 7.79 & 4.48 & 0.69 \\
\hline & & 0.25 & 13.8 & 4.98 & 0.96 \\
\hline & Filters & $\begin{array}{c}\text { Volume } \\
\left(\mathrm{m}^{3}\right)\end{array}$ & $\begin{array}{l}\text { Inflow } \\
\text { (NTU) }\end{array}$ & $\begin{array}{c}\text { After S10 } \\
\text { (NTU) }\end{array}$ & $\begin{array}{c}\text { After S1 } \\
\text { (NTU) }\end{array}$ \\
\hline \multirow[t]{3}{*}{ House 1} & \multirow[t]{3}{*}{$\mathrm{S} 10+\mathrm{S} 1$} & 0 & 11.2 & 2.42 & 0.88 \\
\hline & & 0.12 & 8.07 & 0.42 & 0.47 \\
\hline & & 0.25 & 5.18 & 0.58 & 0.38 \\
\hline \multirow[t]{3}{*}{ House 2} & \multirow[t]{3}{*}{$\mathrm{S} 10+\mathrm{S} 1$} & 0 & 6.30 & 1.33 & 0.82 \\
\hline & & 0.12 & 2.28 & 1.82 & 0.65 \\
\hline & & 0.25 & 3.84 & 1.64 & 0.48 \\
\hline \multirow[t]{3}{*}{ Central tank } & \multirow[t]{3}{*}{$\mathrm{S} 10+\mathrm{S} 1$} & 0 & 5.74 & 2.77 & 0.68 \\
\hline & & 0.12 & 6.28 & 4.77 & 1.13 \\
\hline & & 0.25 & 7.38 & 0.8 & 0.72 \\
\hline
\end{tabular}




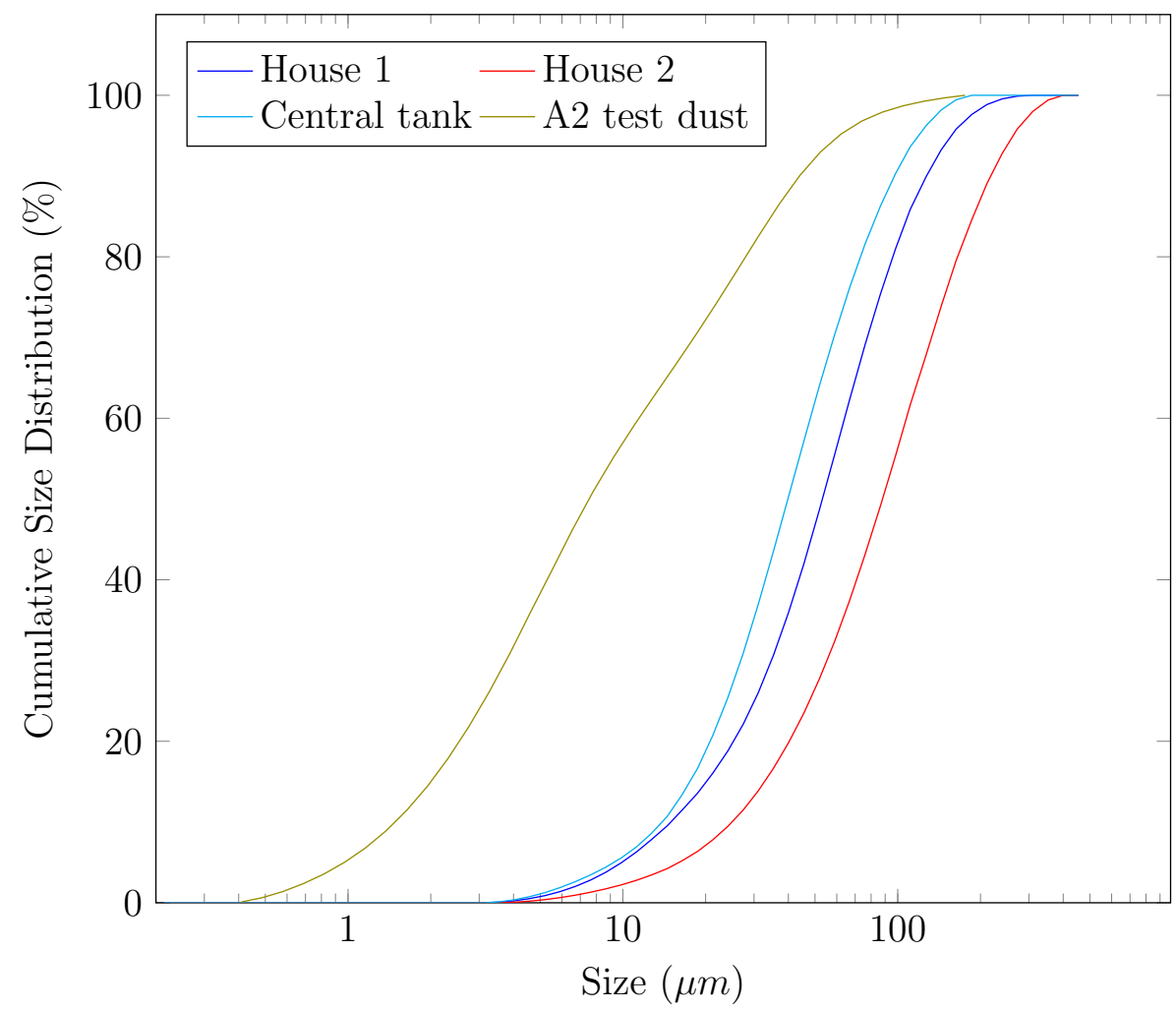

Figure 15: Comparison of PSD of A2 test dust and the particles in samples taken from two houses and one central storage tank in Curiti, Colombia. 


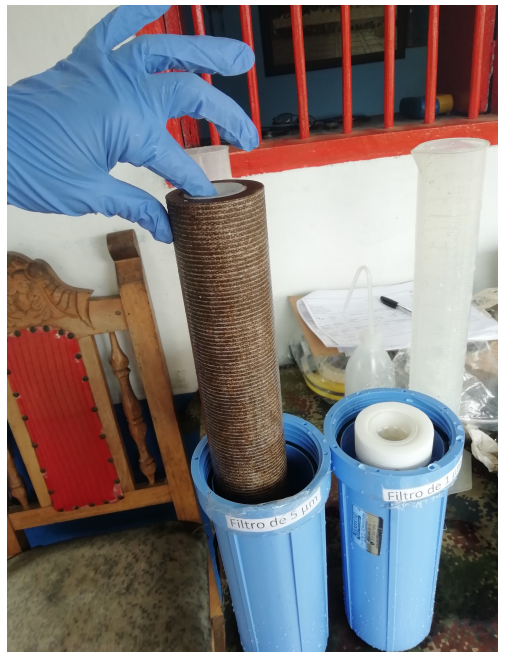

(a) $\mathrm{S} 5+\mathrm{S} 1$

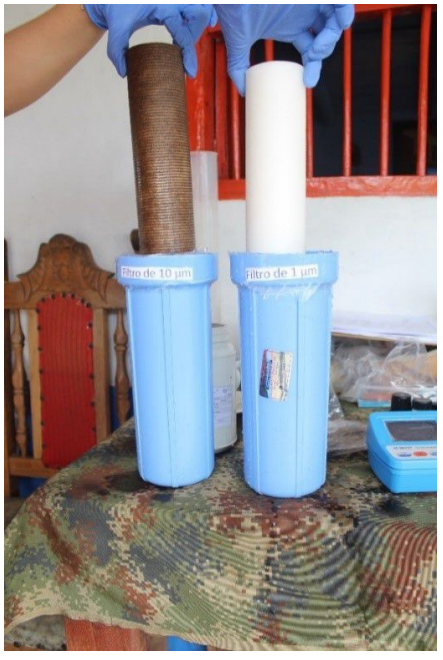

(b) $\mathrm{S} 10+\mathrm{S} 1$

Figure 16: 10, 5 and 1 micron spun filters after the filtration trials in Curiti with natural water. (a) Trial with a 5 and a 1 micron filter $(\mathrm{S} 5+\mathrm{S} 1)$ and (b) trial with a 10 and a 1 micron filter $(\mathrm{S} 10+\mathrm{S} 1)$.

duced industrially to have a specific PSD according to ISO 12103-1, while the size distribution of particles in natural waters varied due to particle-particle interactions. Moreover, PSD only provides information about the fraction of different particle sizes within the sample, not the quantity of particles. Previous work has established a relationship between particle number and turbidity [32, 33], but a fundamental study of this nature was considered beyond the scope of this work.

\section{Conclusion}

The trials demonstrated the general turbidity removal and pressure drop $(\Delta \mathrm{P})$ trends of a range of commercial filters in a study designed to simulate long term performance.

When A2 test dust was used, pleated filters outperformed spun and wound filters reaching the goal of effluent turbidity of $<5 \mathrm{NTU}$, both when the initial turbidity was $40 \pm 10 \mathrm{NTU}$ and with higher initial turbidity of $120 \pm$ 10 NTU. In addition, pleated filters improved sustainability through the opportunity to clean and reuse the cartridge element for at least three cycles while delivering a higher quality effluent output. 
Given the range of particle sizes occurring naturally in water and in the model test dust, we demonstrate that a 'multi-barrier approach' to filtration based systems, results in consistent and reliable turbidity removal and effluent quality.

However, effluent turbidity only reached the WHO HWTS criterion of $<5$ NTU after $0.35 \mathrm{~m}^{3}$ of water was processed using pleated filter elements of 5 and 1 micron. During the initial lag time, water should be discarded until a cake builds up and particle removal reach the target; in practice, this is not feasible in regions where water is not abundant. Future research will be conducted to eliminate or reduce the lag time ensuring that all treated water meets a turbidity threshold of $<5$ NTU. Studying the fluid dynamics in the filter housing will also be undertaken to provide a better understanding of the role of the fluid flow field.

Field tests with natural water demonstrated that the HWT system based upon S5 + S1 filter elements effectively reduced turbidity to less than 1 NTU, well below the 5 NTU recommendation therefore providing water of a suitable turbidity for subsequent UV disinfection. Further work is required to study the effect of seasonality on the PSD of natural water and the associated effect on filter efficiency.

\section{Acknowledgements}

This study is part of SAFEWATER projects supported by Global Challenges Research Fund (GCRF) and UK Research and Innovation (SAFEWATER; EPSRC Grant Reference EP/P032427/1). We also acknowledge support from Ulster University's VCRS Postgraduate Scholarship Scheme (AA) and the Erasmus + Programme (MM). Moreover, the authors would like to thank Helen Lubarsky and Natalia Pichel Mira for their technical support.

\section{References}

[1] WHO, WHO water, sanitation and hygiene strategy 2018-2025, 2018.

[2] WHO \& UNICEF, Progress on drinking water, sanitation and hygiene: 2017 update and SDG baselines, 2017.

[3] WHO, Water quality and health - review of turbidity: information for regulators and water suppliers, 2017. 
[4] J. Christensen, K. G. Linden, How particles affect UV light in the UV disinfection of unfiltered drinking water, American Water Works Association 95 (2003) 179-189.

[5] H. Mamane, J. J. Ducoste, K. G. Linden, Effect of particles on ultraviolet light penetration in natural and engineered systems, Applied Optics 45 (2006) 1844-1856.

[6] H. Mohamed, J. Brown, R. M. Njee, T. Clasen, H. M. Malebo, S. Mbuligwe, Point-of-use chlorination of turbid water: results from a field study in Tanzania, Journal of Water and Health 13 (2015) 544-552.

[7] T. K. Ngai, R. R. Shrestha, B. Dangol, M. Maharjan, S. E. Murcott, Design for sustainable development - Household drinking water filter for arsenic and pathogen treatment in Nepal, Journal of Environmental Science and Health - Part A Toxic/Hazardous Substances and Environmental Engineering 42 (2007) 1879-1888.

[8] M. R. Templeton, R. C. Andrews, R. Hofmann, Removal of particleassociated bacteriophages by dual-media filtration at different filter cycle stages and impacts on subsequent UV disinfection, Water Research 41 (2007) 2393-2406.

[9] WHO, Guidelines for Drinking-water Quality, World Health Organization, 2017.

[10] J. C. Crittenden, R. R. Trussell, D. W. Hand, K. J. Howe, G. Tchobanoglous, MWH's Water Treatment, 2012.

[11] S. Kaur, R. Gopal, W. J. Ng, S. Ramakrishna, T. Matsuura, NextGeneration Fibrous Media for Water Treatment, MRS Bulletin 33 (2008) $21-26$.

[12] US EPA, Small Drinking Water Systems Handbook. A Guide to " Packaged "Filtration and Disinfection Technologies with Remote Monitoring and Control Tools, Technical Report, EPA, 2003.

[13] K. Saxena, U. Brighu, A. Choudhary, Coagulation of humic acid and kaolin at alkaline $\mathrm{pH}$ : Complex mechanisms and effect of fluctuating organics and turbidity, Journal of Water Process Engineering 31 (2019) 100875 . 
[14] E. Sikorska, J. M. Gac, L. Gradon,, Performance of a depth fibrous filter at particulate loading conditions. Description of temporary and local phenomena with structure development, Chemical Engineering Research and Design 132 (2018) 743-750.

[15] T. Sparks, G. Chase, Filters and Filtration Handbook, Elsevier Ltd., 2016.

[16] C. R. O'Melia, W. Stumm, Theory of Water Filtration, American Water Works Association 59 (1967) 1393-1412.

[17] J. H. Raistrick, Fibrous materials for the filtration of liquids, Composites 10 (1979) 206-208.

[18] C. Tien, Principles of Filtration, Elsevier B.V., 2012.

[19] G. Howard, J. Bartram, S. World Health Organization. Water, H. Team, Domestic water quantity, service level and health, 2003.

[20] R. C. Medeiros, N. Fava, B. L. Freitas, L. P. Sabogal-Paz, M. T. Hoffmann, J. Davis, P. Fernandez-Ibañez, J. A. Byrne, Drinking water treatment by multistage filtration on a household scale: Efficiency and challenges, Water Research 178 (2020).

[21] A. Pérez-Vidal, J. Diaz-Gómez, J. Castellanos-Rozo, O. L. UsaquenPerilla, Long-term evaluation of the performance of four point-of-use water filters, Water Research 98 (2016) 176-182.

[22] D. van Halem, H. van der Laan, A. I. Soppe, S. G. Heijman, High flow ceramic pot filters, Water Research 124 (2017) 398-406.

[23] G. Viccione, S. Evangelista, G. de Marinis, Experimental analysis of the hydraulic performance of wire-wound filter cartridges in domestic plants, Water 10 (2018) 1-15.

[24] WHO, WHO International Scheme to Evaluate Household Water Treatment Technologies - Harmonized Testing Protocol: Technology NonSpecific, 2014.

[25] I. M. Hutten, Handbook of Nonwoven Filter Media, Elsevier Ltd., 2016. 
[26] H. H. Kleizen, A. B. de Putter, M. van der Beek, S. J. Huynink, Particle concentration, size and turbidity, Filtration and Separation 32 (1995) 897-901.

[27] S. Evangelista, G. Viccione, O. Siani, A new cost effective, long life and low resistance filter cartridge for water treatment, Journal of Water Process Engineering 27 (2019) 1-14.

[28] M. B. Pawlowicz, J. E. Evans, D. R. Johnson, R. G. Brooks, A study of the efficacy of various home filtration substrates in the removal of microcystin-LR from drinking water, Journal of Water and Health 4 (2006) 99-107.

[29] ISO 4572, Hydraulic fluid power — Filters — Multi-pass method for evaluating filtration performance, 1981.

[30] ISO 16889, Hydraulic fluid power — Filters - Multi-pass method for evaluating filtration performance of a filter element, 2008.

[31] Pall Corporation, Changes in the Presentation of Pall Filter Element Performance Ratings, Technical Report, 2013.

[32] M. Yao, J. Nan, T. Chen, Effect of particle size distribution on turbidity under various water quality levels during flocculation processes, Desalination 354 (2014) 116-124.

[33] W. He, J. Nan, Study on the impact of particle size distribution on turbidity in water, Desalination and Water Treatment 41 (2012) 26-34. 


\section{Supplementary Material}

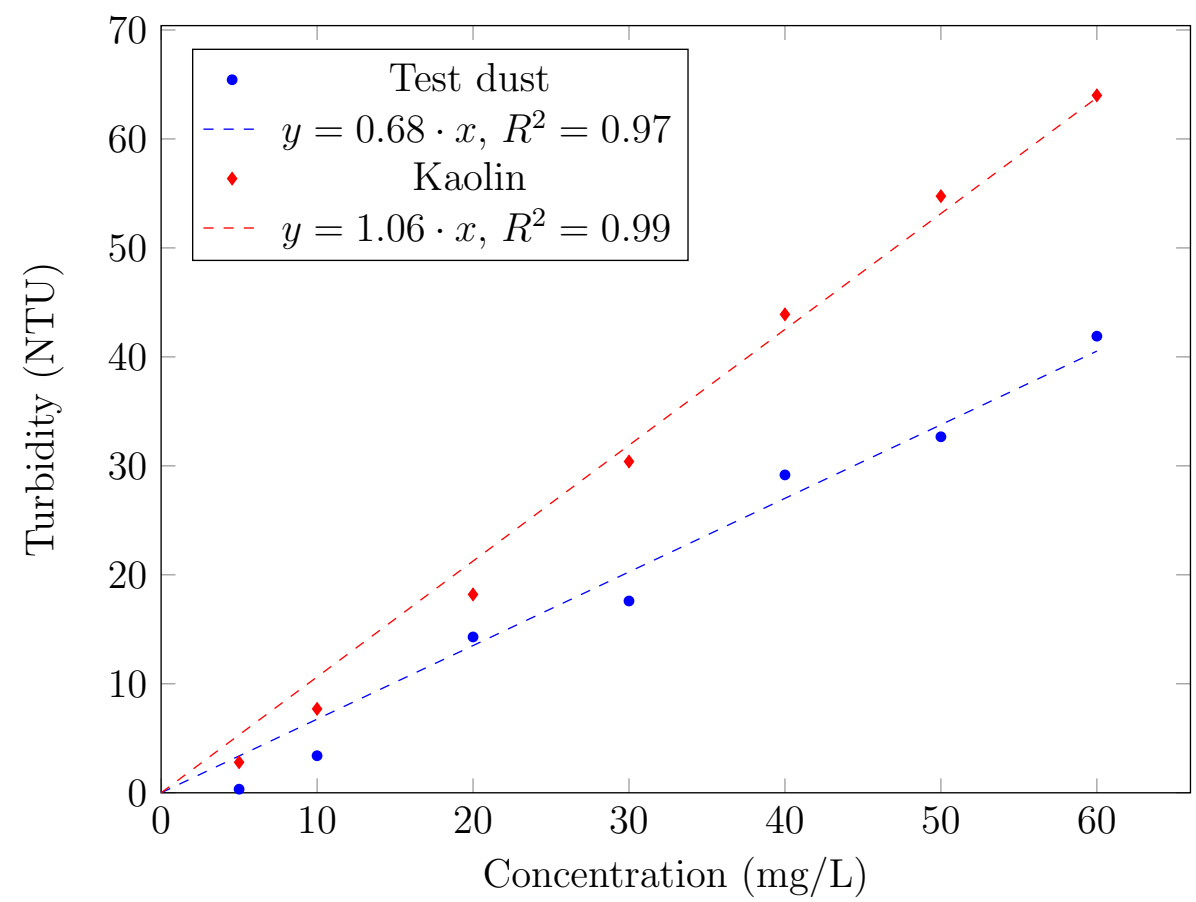

Figure S1: Correlation of A2 test dust and kaolin concentrations with turbidity in tap water with turbidity of 0.00 NTU. 


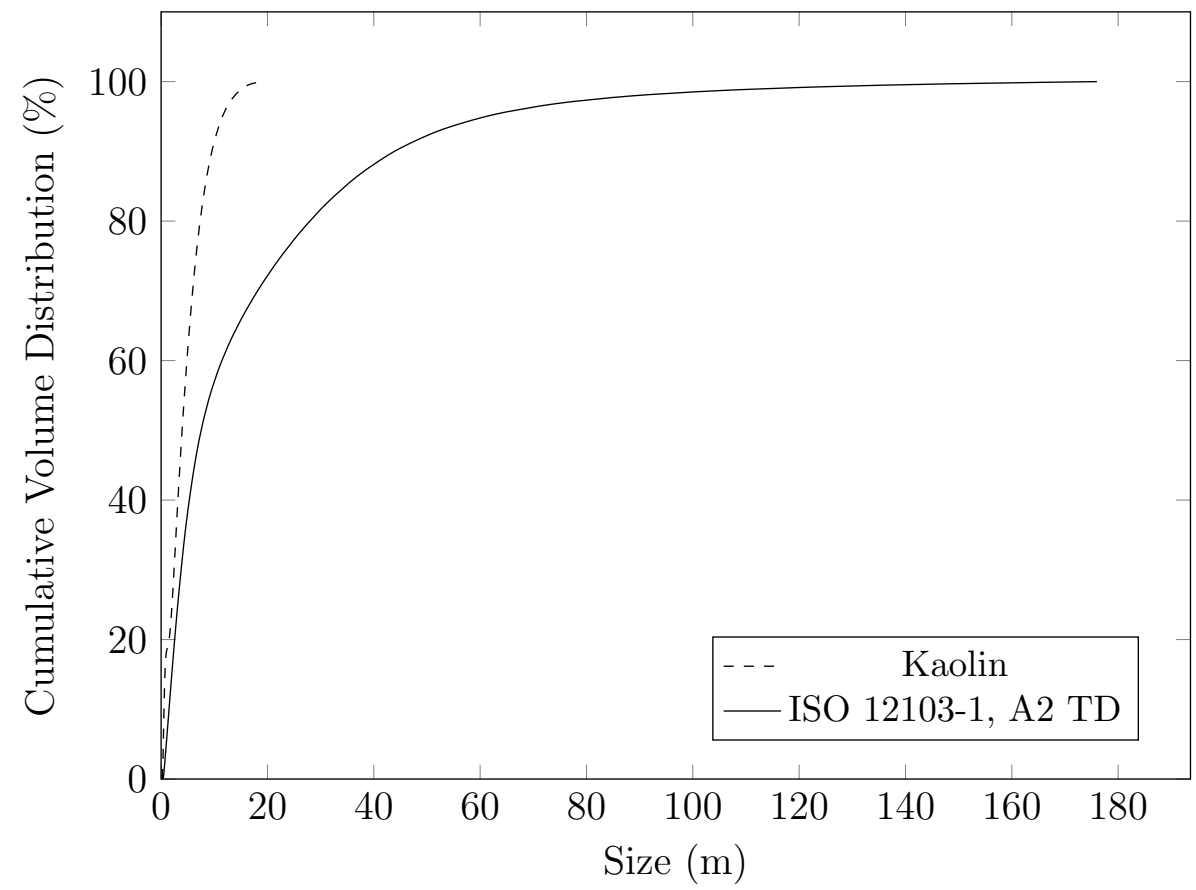

Figure S2: Cumulative volume PSD of A2 test dust and kaolin measured by a particle size analyzers (Mastersizer 2000, Malvern Panalytical).

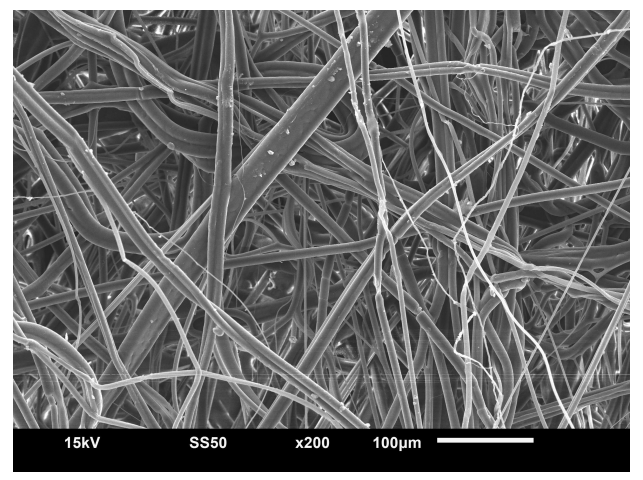

(a)

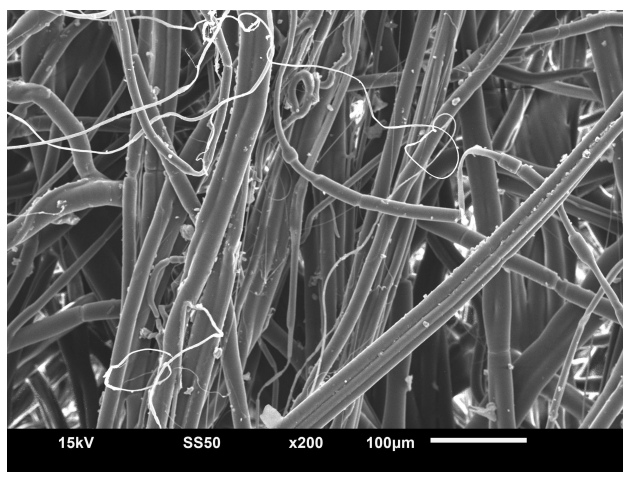

(b)

Figure S3: SEM images of a cross-section of spun filters with different micron ratings: (a) 5 micron and (b) 1 micron. 


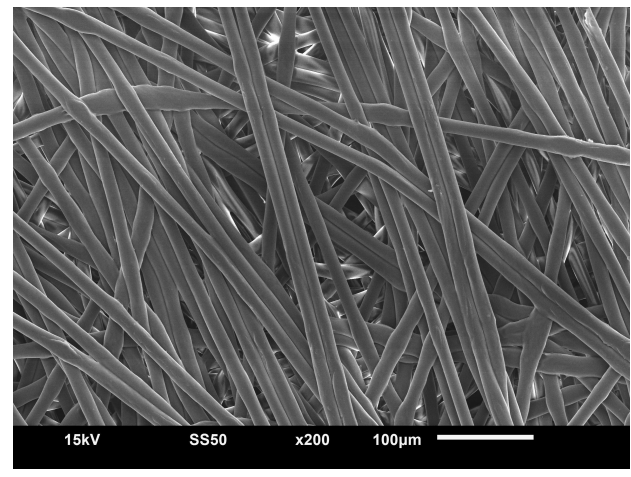

(a)

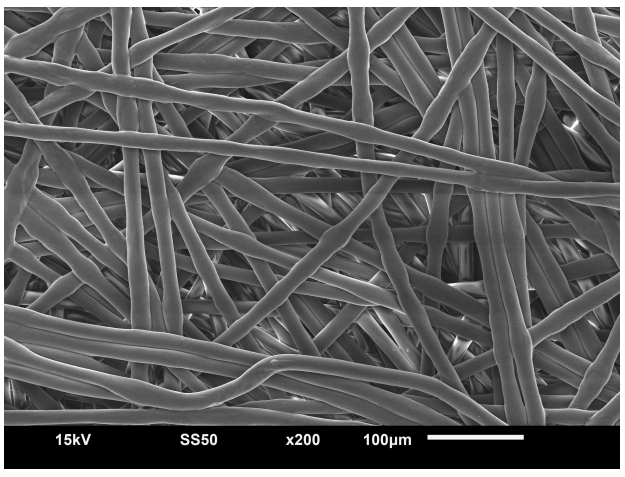

(b)

Figure S4: SEM images of a section of pleated filters with different micron ratings: (a) 5 micron and (b) 1 micron.

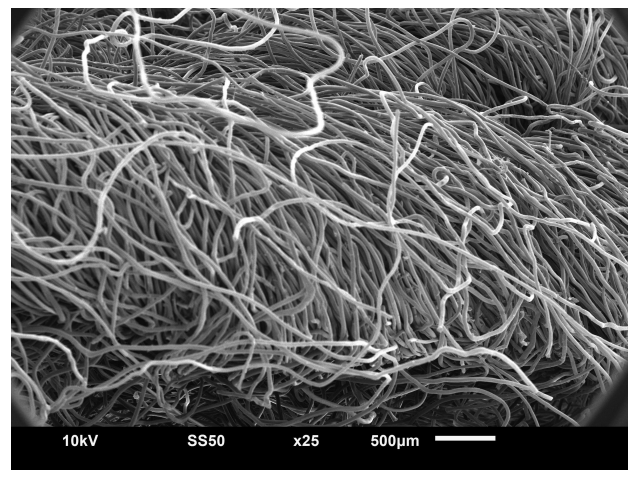

(a)

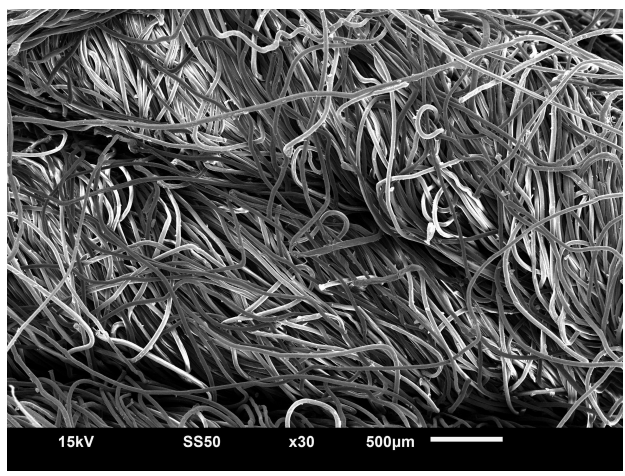

(b)

Figure S5: SEM images of yarns in (a) 5 micron and (b) 1 micron wound filters, showing yarns have different diameters. 


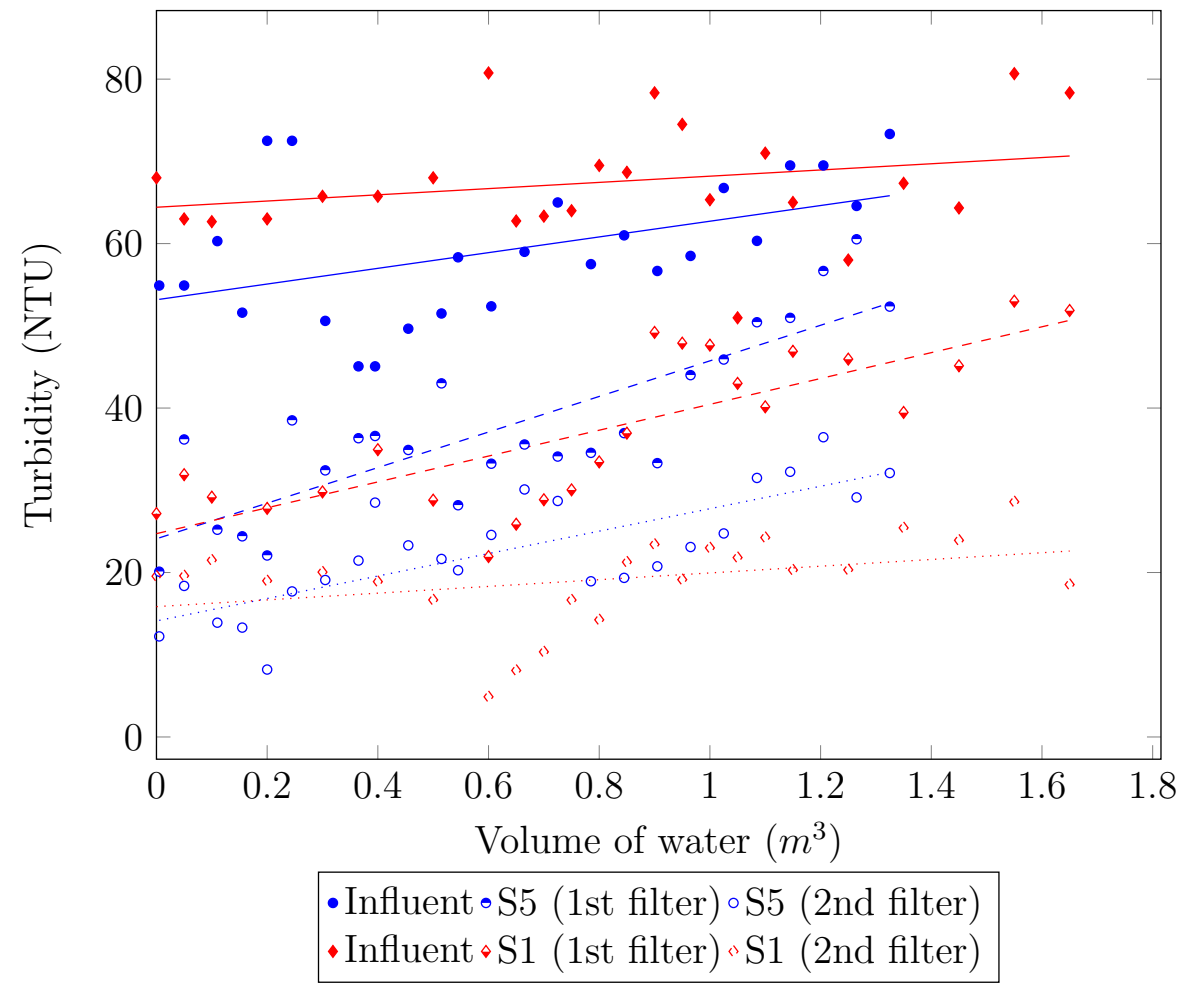

Figure S6: Turbidity measurements of influent and effluent of spun filters against the volume of water treated. S5 + S5 two spun filter elements ( 5 and 5 micron) in series, S1 + S1 two spun filter elements (1 and 1 micron) in series. Kaolin with the same concentration of TD $(60 \mathrm{mg} / \mathrm{L})$ was added; however, as the correlation of kaolin concentration and turbidity is different, the initial turbidity is different as well. 


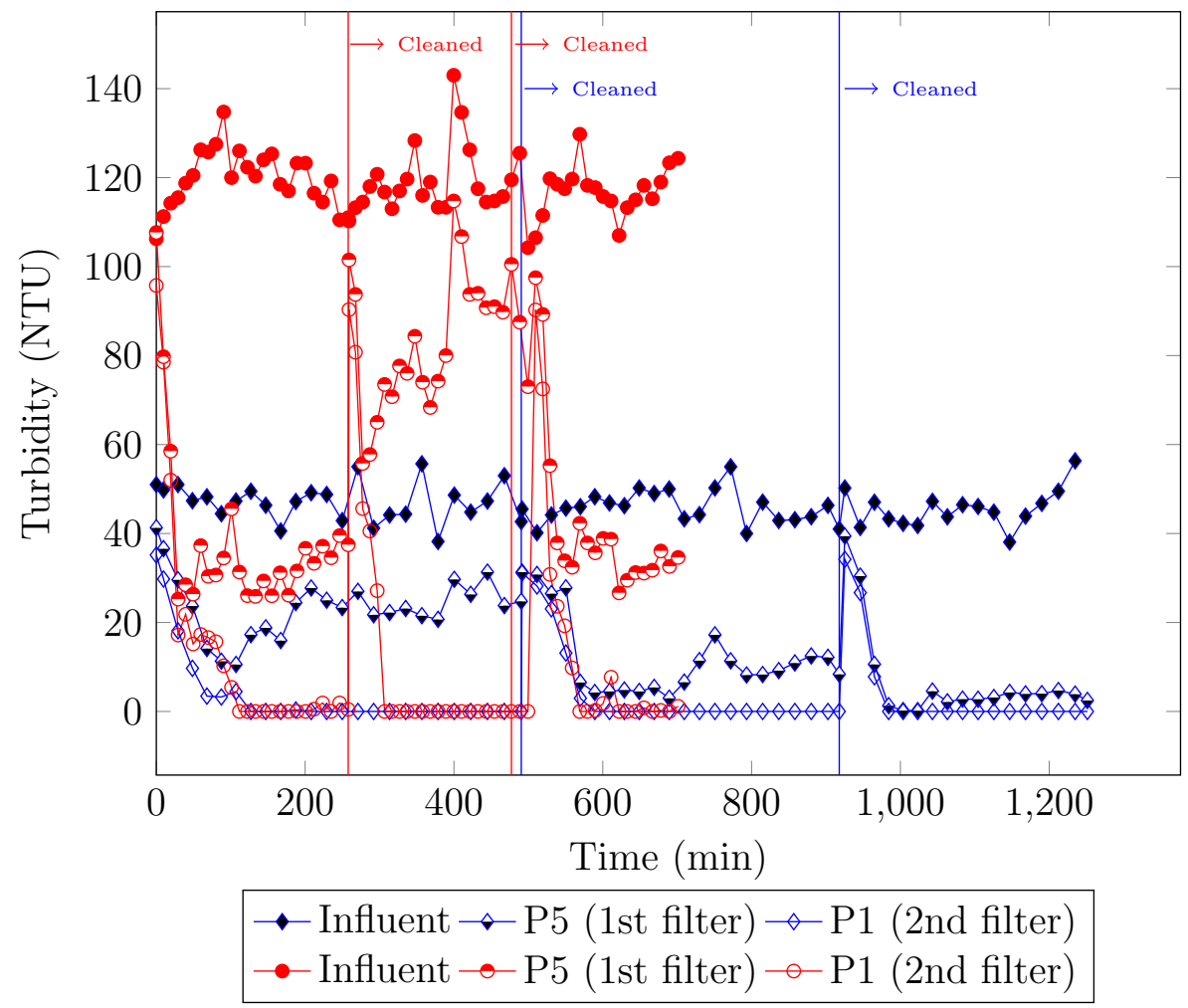

Figure S7: Turbidity measurements of influent and effluent of each pleated filter against experimental time. P5 + P1 (blue) two pleated filter elements (5 and 1 micron) in series and intial turbidity of $40 \pm 10$ NTU, P5 + P1 (red) two pleated filter ( 5 and 1 micron) in series and initial turbidity of $120 \pm 10$ NTU. 